\title{
RUÍdO NAS ÁREAS METROPOLITANAS E URBANIZAÇÃO DE SOLOS NATURAIS - PROMOÇÃO DA HABITAÇÃO NA ÚLTIMA REFORMA DO CÓDIGO FEDERAL DO URBANISMO DE 2017
}

\author{
NOISE IN METROPOLITAN AREAS AND URBANIZATION OF NATURAL SOILS - \\ HOUSING PROMOTION IN THE CONTEXT OF THE LATEST REFORM OF THE 2017 \\ GERMAN FEDERAL CODE ON URBANIZATION
}

Anja Bothe ${ }^{1}$

\begin{abstract}
Resumo
Criticando a reforma de 2017 ao Código Federal do Urbanismo Alemão, analisam-se os recentes instrumentos legais, introduzidos com a finalidade de promover o planeamento e a construção de habitações economicamente acessíveis - nomeadamente, a nova tipologia de qualificação de zonas edificáveis, a área urbana. Nesta reforma admitiu-se uma maior densidade de construção e um maior índice de exposição ao ruído, além de introduzido um procedimento acelerado para planos vinculativos em áreas rústicas. Parte dos instrumentos agora introduzidos contrariam os princípios da poupança de solos naturais, da avaliação ambiental e da participação pública prévia, inscritos no Direito Internacional e no Direito Comunitário. Concluise, por fim, ser mais adequada a promoção da descentralização e da qualidade de vida nas zonas rurais onde abundam já habitações, assim como a intervenção activa no sentido de desenvolver o interior dos perímetros já urbanizados, em vez de realizar compromissos e admitir cedências que degradam os níveis ecológicos e sociais.
\end{abstract}

Palavras-chave: Promoção da Habitação; Planeamento Urbanístico; Direito do Urbanismo Alemão; Poupança de Solos Naturais; Descentralização.

\begin{abstract}
A critical analysis of the latest reform of the 2017 German Federal Code on Urbanization, covering the most recent legal instruments introduced with the objective of promoting the planning and construction of affordable housing. Specifically, an analysis is presented of the new types and qualifications of housing sectors within urban areas. In the latest reform of the Code an allowance was made for a higher density of housing construction and a higher index of noise exposure. Moreover, an accelerated procedure was introduced for planning construction of housing in rustic sectors. Many of the new instruments being introduced go against the principles, included in International and Community Laws, of preservation of natural soils, of adequate evaluation of the impacts on the environment, and of public participation during the early planning stages. The conclusion reached in this paper is that it is preferable to promote decentralization of the process, to preserve and promote the quality of life in rural areas where housing is already present, and to promote active intervention in the continued development of housing within already urbanized areas. This is preferable to accepting compromises and plans

\footnotetext{
${ }^{1}$ Doutora em Direito pela Faculdade de Direito da Universidade de Hamburgo, Alemanha. Investigadora no Centro de Investigação do Departamento de Direito da Universidade Autónoma Ratio Legis. Professora na Universidade Autónoma de Lisboa. Professora na Universidade Atlântica da Barcarena. Email: anjabothe@hotmail.com
} 
that degrade the ecological and social quality of existing urban areas.

Keywords: Housing Development; Urban Planning; German Urban Law; Preservation of Natural Soils; Decentralization.

\section{INTRODUÇÃO E DELIMITAÇÃO DO TEMA}

Em maio de 2017, entrou em vigor a última reforma do Código Federal do Urbanismo Alemão (CFU). Esta reforma introduziu, como tipologia de qualificação de zonas edificáveis, a área urbana. Se esta tipologia tem por principal objetivo a criação de espaços para a construção de habitações, carentes nas zonas mais densamente habitadas na Alemanha, admite, igualmente, uma maior densidade de construção e a admissibilidade de um mais elevado nível de ruído.

Com o objetivo de promover uma mais célere construção de habitação, foi introduzido o instrumento mais criticado da reforma: o procedimento acelerado para a aprovação de um plano vinculativo aplicável às áreas exteriores ao perímetro urbano. Este procedimento dispensa a avaliação ambiental, a compensação ecológica, a participação prévia do público e das autoridades, e a elaboração de um plano vinculativo a partir do plano preparatório. Os opositores deste instrumento consideram-no uma afronta ao princípio da poupança de solos há décadas existente, fundamental no CFU, tal como afirmado na Carta de Leipzig.

Esta reforma introduziu ainda outras alterações, mas, para podermos explicar devidamente os novos instrumentos, limitámos a presente análise àqueles que visam promover a habitação em geral e a habitação das classes média e baixa em particular. Em futuros trabalhos, iremos analisar outros instrumentos introduzidos nesta reforma, nomeadamente, a partir da perspectiva da instrumentalização do turismo e de como pode este constituir uma ameaça à oferta de habitação economicamente mais acessível. Não se abordam igualmente as alterações legislativas exigidas pela Directiva Europeia referente à Avaliação Ambiental Estratégica. Grande parte dessa directiva foi já transposta na lei da avaliação ambiental. 


\section{ENQUADRAMENTO: TIPOS DE PLANOS MUNICIPAIS NA ALEMANHA}

Para determinar as zonas edificáveis, as autoridades locais estão limitadas às tipologias de qualificação definidas no Regulamento de Usos Gerais de Construção² (RUGC). No CFU, além dos planos municipais ${ }^{3}$ preparatórios, ${ }^{4}$ encontram-se previstos três tipos de planos vinculativos para os particulares, a saber, os planos qualificados, ${ }^{5}$ os planos de execução ${ }^{6}$ e os planos simplificados ${ }^{7}$.

No plano municipal preparatório, há que distinguir zonas de uso habitacional, zonas de uso misto, zonas de uso comercial ou industrial, e zonas de uso especial. ${ }^{9}$ Estas quatro

\footnotetext{
2 Regulamento de Usos Gerais de Construção, Baunutzungsverordnung, traduzido por Regulamento Federal sobre a utilização de terrenos com vista à construção, em OLIVEIRA, Fernanda Paula: Análise comparativa das Leis de Solo de Países Europeus, Direção-Geral do Ordenamento do Território e do Desenvolvimento Urbano, Lisboa, 2004. No Artigo 9. do Código Federal do Urbanismo, CFU, cuja epígrafe é "autorização para decretar", lê-se: "O Ministro Federal do Trânsito, Construção e Desenvolvimento Urbano é autorizado a decretar, com o consentimento do Conselho Federal, normas referentes a: 1. Apresentações e determinações nos planos municipais sobre a) $\mathrm{O}$ tipo de uso edificatório; b) As intensidades de uso edificatório e o seu cálculo (...)"

${ }^{3}$ Designamos por municípios, autarquias, câmaras, ou poder local o nível inferior da Administração local, Gemeinde, http://pt.wikipedia.org/wiki/Munic\%C3\%ADpios_da_Alemanha; ver também: OLIVEIRA, Fernanda Paula: Direção Geral do Ordenamento do Território e do Desenvolvimento Urbano, Documento Técnico 8/2011. No entanto, ao nível das circunscrições para fins de estatística, são designadas como LAU 2 as 11.197 Gemeinden alemãs e os 1.457 Gemeindeverbände alemães (associações de municípios).

$4 \quad$ Ver imagens em:
} https://www.google.de/search?q=fl\%C3\%A4chennutzungsplan\&tbm=isch\&tbo=u\&source=univ\&sa=X\&ei

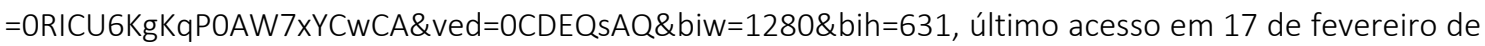
2014; sobre a relação entre o plano preparatório e o plano vinculativo para os particulares, ver: OLIVEIRA, Fernanda Paula: Urbanismo Comparado: o Paradigma do Modelo Alemão, in Conferência "Ordenamento do Território e Revisão dos Planos Diretores Municipais", Figueira da Foz, 8 e 9 de julho de 2003, p. 5.

${ }^{5}$ Artigo 30.ํ, n.o 1, do CFU: Na área de vigência de um plano municipal vinculativo para os particulares, que, autonomamente ou conjuntamente com outras normas urbanísticas, determina no mínimo o tipo e a intensidade do uso edificatório, as superfícies que podem receber edificações, e as áreas para o trânsito local, um projeto é admissível quando não contraria nenhuma destas determinações e quando a infraestruturação é assegurada.

${ }^{6}$ Artigo 30. , n.․ 2, do CFU: Na área de vigência de um plano municipal vinculativo para os particulares elaborado para a implementação de um projeto conforme o $\S 12$, um projeto é admissível quando não contraria este plano e quando a infraestruturação é assegurada.

${ }^{7}$ Artigo 30.ํ, n. 3, do CFU: Na área de vigência de um plano municipal vinculativo para os particulares que não reúna os pressupostos do n.․ 1 (plano municipal vinculativo para os particulares simplificado), aplica-se para a admissibilidade de projetos os artigos 34.ㅇ e 35.ㅇ.

8 Artigo 1., n.o 2, Código Federal do Urbanismo: "Planos territoriais municipais (Bauleitpläne) são o plano preparatório municipal (Flächennutzungsplan) e o plano municipal vinculativo para os particulares (verbindlicher Bebauungsplan), n.o 3: "Os municípios elaboram planos territoriais municipais, quando e na medida em que é necessário para o desenvolvimento e ordenamento urbanístico (...)".

${ }_{9}^{9}$ Artigo 5.o, n. 1, do CFU: No plano municipal preparatório deve ser apresentado, para o território do município na sua íntegra, e em linhas gerais, o tipo de uso do solo que resulta do desenvolvimento urbanístico pretendido em conformidade com as necessidades previsíveis do município. No n. 2 do mesmo artigo: Podem ser apresentados no plano municipal preparatório nomeadamente: ponto 1 . As 
qualificações concretizam-se, tanto no plano municipal preparatório, como no plano municipal vinculativo para os particulares, em dez tipos de áreas: em áreas parcamente habitadas, áreas de habitação "puras", áreas gerais ou especiais de habitação, áreas de aldeia, áreas mistas, áreas centrais, áreas comerciais, áreas industriais, áreas especiais. ${ }^{10}$

De acordo com o RUGC, cada tipo de área tem específicas funções urbanísticas; pode admitir, regular ou excepcionalmente, um conjunto determinado de projetos; e, referindo-se à área de implantação, ${ }^{11}$ à área de construção ${ }^{12}$ e à volumetria de construção ${ }^{13}$, estabelece o limite máximo admitido. ${ }^{14}$

Quanto aos valores máximos de ruído para cada tipologia de área, há que atender ao Regulamento sobre o Ruído. ${ }^{15}$

\section{A NOVA QUALIFICAÇÃO DE ZONAS EDIFICÁVEIS: A ÁREA URBANA}

Na estrita relação entre a densidade máxima de edificações e o valor máximo de ruído permitido, situa-se a área urbana, como nova qualificação de zona edificável. ${ }^{16}$ Durante o dia, nesta área, os valores máximos de emissão de ruído são 3 decibéis mais altos que nas áreas de aldeia, nas áreas mistas e centrais ${ }^{17}$, tal como admite, nas zonas de habitação, um valor de mais 8 decibéis ${ }^{18} .{ }^{19}$ Os autores desta legislação sublinham não ter sido posto em causa o princípio da

zonas previstas para a construção conforme o tipo geral de uso edificável (zonas edificáveis Bauflächen), conforme o tipo especial de uso edificável (áreas edificáveis - Baugebiete), e igualmente as intensidades gerais do uso edificável.

${ }^{10}$ Artigo 9.․ n. ․ 1, do CFU: No plano municipal vinculativo para os particulares podem ser determinados por motivos urbanísticos: ponto 1. O tipo e a intensidade do uso edificatório; ponto 2. A tipologia de construção, as zonas onde pode e onde não pode haver construção, e a localização das construções.

11 Grundflächenzahl.

12 Geschossflächenzahl.

13 Baumassenzahl.

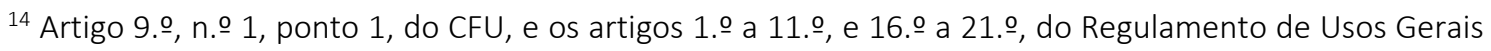
de Construção.

15 Technische Anleitung Lärm Instruções Técnicas Ruído, Sechste Allgemeine Verwaltungsvorschrift zum Bundes-Immissionsschutzgesetz Sexto Regulamento Geral da Lei Federal da Proteção contra as Imissões (Technische Anleitung zum Schutz gegen Lärm - TA Lärm), de 26 de agosto de 1998, Gemeinsames Ministerialblatt, GMBI Boletim Comum dos Ministérios, 1998 N. 26, p. 503 alterado pelo Regulamento de 1 de junho de 2017,

http://www.verwaltungsvorschriften-im-internet.de/bsvwvbund_26081998_IG19980826.htm

16 Krautzberger, Michael/ Stüer, Bernhard, Entwurf der Städtebaurechtsnovelle 2017, p. 2, http://www.stueer.business.t-online.de/aufsatzc/baur0417.pdf

${ }_{17}$ Misch-, Kern- und Dorfgebiet.

${ }^{18}$ Allgemeines Wohngebiet, Kleinsiedlungsgebiet.

19 Ponto 6.1 das Instruções Técnicas Ruído - Valores máximos de Imissão para os lugares de imissão medidas no exterior do edifício. ("Die Immissionsrichtwerte für den Beurteilungspegel betragen für Immissionsorte außerhalb von Gebäuden... »). 
proteção elevada contra emissões ${ }^{20}$ - aliás, continuam a ser medidos os valores de ruído junto a janela aberta, não sendo pertinente a proteção instalada pelo edifício recetor.

Houve, no entanto, propostas para promover a proteção passiva em detrimento da proteção ativa; assim, em vez de impor limites às instalações emitentes de ruído (proteção ativa), considerou-se a possibilidade de exigir ao habitante da área envolvente que instalasse mecanismos de proteção contra o ruído de que é vítima (proteção passiva).

Quanto aos valores máximos de densidade de construção, nas áreas urbanas admite-se um índice de ocupação de $0,8^{21}$ e uma área máxima de construção de 3,022,23 nas zonas de aldeia e mistas, o índice de ocupação é 0,6 e a área máxima de construção é 1,2; nas áreas centrais, o índice de ocupação é 1,0 e a área máxima de construção é idêntica à da área urbana; para as zonas de habitação, o índice de ocupação é de 0,4 e a área máxima de construção é de $1,2 . .^{24}$

Assim, o legislador tipificou a área urbana entre as coordenadas atribuídas para as áreas mista e central. ${ }^{25}$

Para além dos valores máximos admitidos, a qualificação de área urbana não exige a equivalência ou o equilíbrio na combinação de usos gerais de construção ${ }^{26}{ }^{27}$ Resulta, aliás, da descrição desta nova qualificação de zona que a mesma visa o desenvolvimento de áreas com usos diversos, não sendo um instrumento para zonas que ainda se mostram sem edificações e

20 DEUTSCHER BUNDESTAG, Parlamento Federal Alemão, Referência 18/10942, Gesetzentwurf der Bundesregierung, Proposta de lei do Governo Federal, Entwurf eines Gesetzes zur Umsetzung der Richtlinie 2014/52/EU im Städtebaurecht und zur Stärkung des neuen Zusammenlebens in der Stadt, Proposta da lei para a transposição da Diretiva 2014/52/EU no Direito Federal do Urbanismo e para o reforço do novo tipo de convívio na cidade, 23 de janeiro de 2017, p. 29, http://dip21.bundestag.de/dip21/btd/18/109/1810942.pdf

${ }^{21}$ Artigo 19, n.o 1, do RUGC: O índice de ocupação são os metros quadrados de implantação por metro quadrado de lote. No n.o 2 do mesmo artigo: A área de implantação indica a parte do lote - calculado com base no $n . .1$ - que pode ser ocupado com construções.

22 Artigo 20, n.o 2, do RUGC: A área de construção indica os metros quadrados de construção por cada metro quadrado de lote.

${ }^{23}$ Artigo 17, n. 1, do RUGC.

${ }^{24}$ Mais especificamente são estes os valores máximos para as zonas de habitação "pura" e as áreas gerais de habitação, sendo os valores das zonas especiais de habitação de 0,6 e 1,6, i.e., quase a metade da densidade de construção prevista em comparação com o instrumento novo da área urbana.

${ }^{25}$ Isto reflete-se já na técnica legislativa de colocar o novo artigo 6, alínea a, do RGCU entre o artigo 6 sobre a área mista e o artigo 7 da área central.

${ }^{26}$ Die Nutzungsmischung muss nicht gleichgewichtig sein.

27 De acordo com a segunda parte do nova redacção do artigo 6, alínea a, do RUGC. Cita-se a primeira parte: As áreas urbanas servem a habitação e ao comércio e a instalações sociais, culturais e outras, que não interferem substancialmente com o uso da habitação. Já de acordo com o n.o 2, são permitidos 1 . Edifícios residenciais, 2. Edifícios comerciais e de escritórios, 3. Indústria de varejo, bares e restauração, bem como estabelecimentos da indústria hoteleira, 4. outras empresas comerciais, 5. Instalações para administrações, bem como para fins eclesiásticos, culturais, sociais, de saúde e desportivos. 
sem planos vinculativos. ${ }^{28}$

\section{Da recepção pública da nova tipologia das áreas urbanas}

A introdução das áreas urbanas foi acolhida positivamente pela generalidade dos das entidades públicas e/ou privadas. Contudo, ao facilitar o planeamento e a construção em zonas com uma certa densidade, a crescente concentração habitacional nas zonas centrais das cidades provoca conflitos de usos e de direitos de usos, inclusive a proteção contra o ruído, especialmente quando o uso habitacional se vai aproximando aos outros usos. ${ }^{29}$

Coloca-se, assim, o seguinte dilema: ou se prossegue a rigorosa proteção contra o ruído em face do actual uso habitacional, ou se, diminuindo o grau daquela proteção, se aproveita os espaços baldios. O legislador optou pelo aproveitamento daqueles espaços, com a consequente diminuição do nível de proteção contra o ruído. Assim, no âmbito do instrumento das áreas urbanas, as câmaras municipais têm o poder de dispor de espaços devolutos e baldios, que constituíam barreiras naturais contra o ruído, e destiná-los à habitação. No entanto, há que ter presente que a cidade de usos mistos se caracteriza pela existência de curtas distâncias entre as zonas residenciais e os locais de trabalho, de comércio, lazer, cultura, ensino e administração, sendo que aquela opção permite aproveitar solos já urbanizados, em vez de beneficiar a transformação e urbanização de espaços naturais.

\section{Advertências referentes ao novo instrumento das áreas urbanas}

Todos os cidadãos têm direito à proteção contra emissões sonoras. Não se pode confundir a necessidade de uma maior flexibilidade no planeamento e na construção com a normalização do processo de designação, como área urbana, de qualquer espaço que não permita o planeamento de zonas mistas ou habitacionais devido a ruídos industriais. ${ }^{30}$ Desse modo, tratar-se-ia de um instrumento legal duvidoso que diminui um direito fundamentalmente relacionado com a saúde e a qualidade de vida. Na verdade, as habitações economicamente mais acessíveis passariam a situar-se em zonas mais densamente povoadas e,

\footnotetext{
${ }^{28}$ Krautzberger, Michael/ Stüer, Bernhard, Entwurf der Städtebaurechtsnovelle 2017, p. 6

${ }^{29}$ Parlamento Federal Alemão, Referência 18/10942, Proposta de lei do Governo Federal, Proposta da lei para a transposição da Diretiva 2014/52/EU no Direito Federal do Urbanismo e para o reforço do novo tipo de convívio na cidade, 23 de janeiro de 2017, p. 32.

${ }^{30}$ Steinke, Michael/Zemke, Reinhold, Stadt/Ökonomie/Recht, Cidade/ Economia/Direito, Kommentar zur Städtebaurechtsnovelle 2017, Anotações a Reforma do Direito do Urbanismo 2017, Zu den Änderungen des BauGB und der BauNVO, Acerca das alterações do CFU e do RUGC, 16 de maio de 2017, http://stadtoekonomie-recht.de/\%c2\%a7-kommentar/kommentar-zur-staedtebaurechtsnovelle-2017/
} 
portanto, sujeitas a um mais elevado grau de ruído. Assim, entendemos que a solução encontrada para as áreas urbanas equacionou ponderadamente a necessidade de criar mais habitações com a crescente densificação populacional e a inevitável produção de mais ruído.

\section{MISSÕES E INTERESSES NO PLANEAMENTO URBANÍSTICO}

A principal finalidade do planeamento urbanístico é valorizar e ponderar todos os interesses envolvidos, nomeadamente, ambientais, económicos, sociais e culturais. ${ }^{31}$ Assim, o CFU define as respetivas prioridades de forma geral:

"Os planos urbanísticos devem garantir um desenvolvimento urbanístico sustentável, que leva à harmonização das preocupações sociais, económicas e ecológicas com responsabilidade também para com as gerações futuras, e a um uso dos solos socialmente justo sob respeito pelas necessidades habitacionais da população, e que serve ao bem comum." (Artigo 1, n.․5, do CFU) ${ }^{32}$

Com a reforma de 2017, desenvolveu-se a resposta às necessidades habitacionais da população, introduzindo-se, entre outras, a tutela específica das famílias numerosas:

“Na elaboração dos planos urbanísticos devem ser tidas em conta nomeadamente: 1. As exigências gerais para um ambiente saudável de habitação e de trabalho, e a segurança da população para habitar e trabalhar. 2. As necessidades habitacionais, nomeadamente também das famílias com várias crianças, a criação e a manutenção de estruturas socialmente estáveis dos habitantes, a criação de propriedade imobiliária de amplas partes da população, ..." (Artigo 1$, n. 6 , do $\mathrm{CFU})^{33}$

Na verdade, a reforma de 2017 teve por finalidade responder à falta de habitações acessíveis nas áreas metropolitanas e outras cidades de maior dimensão. Nas regiões economicamente mais dinâmicas, o uso de imóveis para comércio e serviços compete

\footnotetext{
${ }^{31}$ Bothe, Anja, Direito do Urbanismo, do Ordenamento do Território e dos Solos em Portugal e na Alemanha, JURISMAT, Portimão, n.․ 4, 2014, p. 289, 296.

32 Artigo 1, n.o 5 CFU: "Die Bauleitpläne sollen eine nachhaltige städtebauliche Entwicklung, die die sozialen, wirtschaftlichen und umweltschützenden Anforderungen auch in Verantwortung gegenüber künftiger Generationen miteinander in Einklang bringt, umd eine dem Wohl der Allgemeinheit dienende sozialgerechte Bodennutzung unter Berücksichtigung der Wohnbedürfnisse der Bevölkerung gewährleisten." A parte itálica foi introduzida pela reforma de 2017.

${ }^{33}$ Artigo 1, n. 6 CFU: "Bei der Aufstellung der Bauleitpläne sind insbesondere zu berücksichtigen: 1. Die allgemeinen Anforderungen na gesunde Wohn- und Arbeitsverhältnisse und die Sicherheit der Wohnund Arbeitsbevölkerung, 2. Die Wohnbedürfnisse der Bevölkerung, insbesondere auch von Familien mit mehreren Kindern, die Schaffung und Erhaltung sozial stabiler Bewohnerstrukturen, die Eigentumsbildung weiter Kreise der Bevölkerung und die Anforderungen kostensparenden Bauens sowie die Bevolkerungsentwicklung." A parte itálica foi introduzida pela reforma de 2017.
} 
directamente com o uso habitacional, que, por ser menos lucrativo, se mostra atrofiado. ${ }^{34} \mathrm{Na}$ verdade, é como se o legislador tivesse sido chamado a intervir para proteger o uso mais fraco, neste caso, o uso para fins de habitação. A promoção das necessidades habitacionais da população constitui uma das finalidades programáticas de um Estado Social de Direito: a habitação é mais do que o lugar onde se dorme e come, "ela preenche funções não apenas numa perspetiva de saúde, mais igualmente num sentido espiritual e social. Ela é a área da vida extremamente pessoal do Homem e da sua família. Para além disto, o tipo de habitação do Homem influencia a sua postura para com as instituições estatais, tendo por isto uma dimensão eminentemente política." ${ }^{35}$

Tendencialmente, no mercado da habitação, os clientes mais fracos são as famílias numerosas: é escassa a oferta de casas com um maior número de assoalhadas, quanto mais a preços acessíveis. Simultaneamente, o crescimento demográfico desencadeia preocupações atinentes ao bem comum da população, com manifestos contornos político-económicos, dado que o rejuvenescimento da força de trabalho sempre acarretará vantagens ao nível da composição do salário.

\section{DISCRICIONARIEDADE DO PODER LOCAL NA ELABORAÇÃO DE PLANOS VINCULATIVOS PARA OS PARTICULARES}

De qualquer modo, as prioridades e os interesses reais refletem-se nos planos urbanísticos previstos na lei, a saber, no plano preparatório e nos planos vinculativos para os particulares, na sua tripla configuração. ${ }^{36}$ Todos os 11.197 municípios alemães têm um plano preparatório. A elaboração de um plano sujeita-se à discricionariedade do poder local, ${ }^{37} \mathrm{o}$ mesmo sucedendo para as diversas etapas do planeamento informal. ${ }^{38}$ Consequentemente, a conceção de planeamento pela autarquia é decisiva para a gestão do espaço e para a política de

\footnotetext{
${ }^{34}$ Comparar Oebbeke, Alfons, Baulinks - unabhängiges Baufachmagazin, Links referentes a Construção Revista Técnica da Construção, Kaum Wohnungsleerstand in Grossstädten, Nas cidades grandes quase não há habitações vagas, 6.12.2016, https://www.baulinks.de/webplugin/2016/1775.php4

35 Söfker, Wilhelm in Ernst, Werner/ Zinkahn, Willy/ Bielenberg, Walter/ Krautzberger, Michael: Baugesetzbuch - Código Federal do Urbanismo anotado, Beck, 124 complement, 2017, § 1, anotação 120.

${ }^{36}$ Ver supra capítulo 2.

${ }^{37}$ Artigo 1.․, n.o 2 Código Federal do Urbanismo: "Planos territoriais municipais (Bauleitpläne) são o plano preparatório municipal (Flächennutzungsplan) e o plano municipal vinculativo para os particulares (verbindlicher Bebauungsplan), n.o 3: "Os municípios elaboram planos territoriais municipais, quando e na medida em que é necessário para o desenvolvimento e ordenamento urbanístico (...)".

38 Bothe, Anja, A classificação e a qualificação do solo no direito do urbanismo alemão, JURISMAT, Portimão, n.o 5, 2014, p. 271, 272.
} 
ordenamento do território. ${ }^{39}$ Não existindo nenhum plano vinculativo para os particulares, a admissibilidade de projetos assenta na envolvente física e social existente. ${ }^{40}$ Tratando-se de áreas interiores ao perímetro urbanizado, qualquer projeto deve preencher cumulativamente os seguintes requisitos: ${ }^{41}$

“i. Deve-se tratar de áreas urbanas consolidadas / áreas edificadas no seu conjunto,

ii. O projeto deve-se inserir na envolvente próxima,

iii. Para avaliar a inserção na envolvente, deve-se, entre outros aspetos, ter em conta o tipo e a intensidade do uso edificatório, a tipologia de construção e a área de implantação;

iv. As infraestruturas, nomeadamente a acessibilidade, devem ser garantidas;

v. As condições habitacionais e de trabalho devem ser salvaguardadas; e vi. A imagem da localidade não pode ficar prejudicada.

De modo a interpretar e determinar os limites destas exigências, foi produzido um imenso acervo jurisprudencial." (BOTHE, 2014) 42

\section{ISENÇÃO DA EXIGÊNCIA DA OBRIGAÇÃO DA INSERÇÃO NA ENVOLVENTE}

O grau de exigência da inserção na envolvente foi mitigado com as reformas do CFU de 2007 e 2013, de modo a privilegiar o desenvolvimento de áreas já edificadas em detrimento da consumpção de solos. A reforma de 2017 veio ampliar o domínio da isenção da obrigação da inserção na envolvente: se anteriormente se aplicava apenas às alterações de uso de imóveis para empresas de comércio e de ofício para fins habitacionais, aplica-se agora a qualquer edifício e a qualquer uso que venha a ser alterado para o uso habitacional, ${ }^{43}$ abrangendo-se

\footnotetext{
${ }^{39}$ Acórdãos do Tribunal Federal Administrativo de..., ver Söfker in $\S 1$ an.30.

40 Artigo 30, n. 3, do CFU.

${ }^{41}$ Artigo 34, n.o 1, do CFU: Artigo 34. Admissão de projetos dentro do perímetro urbano, isto é dentro de áreas edificadas - n. 1 Dentro de áreas edificadas no seu conjunto, um projeto é admissível quando se insere em conformidade com o tipo e a intensidade do uso edificatório, e com a tipologia de construção e a superfície que se pretende edificar, nas características da envolvente próxima, e quando é garantida a infraestruturação.

${ }^{42}$ Bothe, Anja, A classificação e a qualificação do solo no direito do urbanismo alemão, JURISMAT, Portimão, n.․ 5, 2014, p. 271, 276, 277.

${ }^{43}$ Artigo 34, n. 3 , alínea a, do CFU novo: Pode haver, em casos individuais, um afastamento da exigência da inserção nas características da envolvente próxima, segundo o n.o 1, primeira parte, se o afastamento preenche os seguintes pressupostos: ponto 1: 0 afastamento serve um dos seguintes projetos: a) aumento, alteração, alteração de uso ou renovação de uma empresa de comércio ou de ofício, que tenha sido estabelecido de forma legal, b) aumento, alteração ou renovação de um edifício legalmente construído e que serve para fins habitacionais, c) alteração de uso de uma instalação legalmente construída e que serve para fins habitacionais, inclusive as alterações e renovações necessárias,

Ponto 2: Urbanisticamente defensível aceitável, e ponto 3: Em harmonia com os interesses públicos tendo também em conta os interesses dos vizinhos. A primeira parte deste artigo não se aplica às empresas a retalho, que poderão afetar ou prejudicar as possibilidades de abastecimento próximo dos
} 
igualmente as alterações e renovações necessárias. Compreendidos nesta previsão estão edifícios públicos, como escolas, igrejas, pavilhões desportivos, centros paroquiais e de cidadãos, ou alojamentos de refugiados. ${ }^{44}$

No âmbito da elaboração da nova legislação pediu-se a colaboração de seis autarquias para realizar um teste prático. Tendo por referência as condições específicas das suas localidades, essas autarquias refletiram sobre os instrumentos legais propostos. Quanto à ampliação da isenção da obrigação da inserção, nenhuma autarquia conseguiu configurar uma situação em que aquela seria aplicável, até porque a conversão de edifícios públicos em habitações já era possível com a legislação anterior. ${ }^{45}$

Ainda assim, três câmaras alertaram para o facto de aquele novo instrumento poder vir a obrigar as autarquias à realização desnecessária de planeamento, ${ }^{46}$ de modo a evitar as imposições resultantes da legislação, em especial, quanto ao alojamento de refugiados, cuja caducidade está legalmente prevista para 31 de dezembro de $2019 .{ }^{47}$ Esta legislação foi aprovada para responder à súbita necessidade de oferecer alojamento a refugiados, nela se prevendo a possibilidade de criação de alojamentos para refugiados em zonas industriais. Se a

consumidores das populações, seja no município onde se pretende localizar o projeto, seja num outro município. (As partes itálicas foram introduzidas pela reforma de 2017)

(3a) Vom Erfordernis des Einfügens in die Eigenart der näheren Umgebung nach Absatz 1 Satz 1 kann im Einzelfall abgewichen werden, wenn die Abweichung 1. einem der nachfolgend genannten Vorhaben dient: a) der Erweiterung, Änderung, Nutzungsänderung oder Erneuerung eines zulässigerweise errichteten Gewerbe- oder Handwerksbetriebs, b) der Erweiterung, Änderung oder Erneuerung eines zulässigerweise errichteten, Wohnzwecken dienenden Gebäudes oder c) der Nutzungsänderung einer zulässigerweise errichteten baulichen Anlage zu Wohnzwecken, einschließlich einer erforderlichen Änderung oder Erneuerung, 2. städtebaulich vertretbar ist und 3. auch unter Würdigung nachbarlicher Interessen mit den öffentlichen Belangen vereinbar ist.

${ }^{44}$ Battis, Ulrich/ Mitschang, Stephan/Reidt, Olaf, Das Gesetz zur Umsetzung der Richtlinie 2014/52/EU im Städtebaurecht und zur Stärkung des neuen Zusammenlebens in der Stadt (BauGB-Novelle 2017), A lei da transposição da Diretiva 2014/52/UE no Direito do Urbanismo e para o reforço do novo tipo de convívio na cidade (Reforma do Código Federal do Urbniamo 2017), NVWZ Revista Nova da Administração, 2017, p. 817,823 .

45 Utilizando os números 1 ou 2 do artigo 34, do CFU, Deutsches Institut für Urbanistik, Instituto Alemão para Urbanística, cliente da elaboração do estudo: Bundesinstitut für Bau-, Stadt- und Raumforschung, Instituto Federal para a investigação referente a construção, a cidade e aos espaço: Planspiel zur Städtebaurechtsnovelle 2016/2017, Teste prático da aplicação do projeto de lei a casos concretos através da administração e outros participantes envolvidos, no total observaram representantes de seis municípios 30 exemplos, 31.1.2017, p. 89, https://difu.de/publikationen/2017/planspiel-zurstaedtebaurechtsnovelle-2016-2017.html.

${ }^{46}$ Que a câmara poderia não considerar necessário sem a existência do novo instrumento.

47 Deutscher Bundestag, Parlamento Federal Alemão, Gesetz über Massnahmen im Bauplanungsrecht zur Erleichterung der Unterbringung von Flüchtlingen, Lei de Medidas no Direito do Urbanismo para facilitar o alojamento de refugiados, de 20 de novembro de 2014, BGBI. I, Boletim Federal I, p. 1748, https://www.bgbl.de/xaver/bgbl/start.xav?start=\%2F\%2F*\%5B\%40attr_id\%3D\%27bgbl114s1748.pdf\%27 \%5D\#_bgbl_\%2F\%2F*\%5B\%40attr_id\%3D\%27bgbl114s1748.pdf\%27\%5D_1506079123836. 
referida isenção pode vir a permitir o reaproveitamento das instalações dos refugiados para usos habitacionais quando deixarem de ser precisas para esse fim, receia-se, igualmente, que venha a degradar os requisitos de construção aplicáveis a zonas com uso habitacional convencional. ${ }^{48}$

\section{DISTINÇÃO ENTRE INTERIOR E EXTERIOR ÀS ÁREAS EDIFICADAS}

Para os espaços sem plano vinculativo, é fundamental a distinção entre o interior ${ }^{49}$ e o exterior $^{50}$ às áreas edificadas - uma tradução menos literal poderia designar, por um lado, o solo urbano e urbanizável e, por outro, o solo rústico.

“Na área exterior, um projeto apenas é admissível, quando se encontra garantida a infraestruturação suficiente e quando: 1. serve para um empreendimento de agricultura ou de silvicultura, e ocupa apenas uma parte subordinada da área do empreendimento (...)" - Artigo 35, n.. 1, do CFU). ${ }^{51}$

Nos pontos 2 a 8, o mesmo artigo elenca os projetos privilegiados neste tipo de área. Significa isto que, nas áreas sem planos vinculativos e fora do perímetro urbano, não se admite, em princípio, construções. Esta orientação constitui a maior distinção em relação às áreas interiores do perímetro urbano. Quando uma câmara municipal pretende transformar solo rústico em solo urbanizável, é obrigada a elaborar um plano vinculativo, o que implica a ponderação de todas as prioridades elencadas no CFU. ${ }^{52}$

\section{O INSTRUMENTO MAIS CRITICADO DA REFORMA: O PROCEDIMENTO ACELERADO PARA PLANOS VINCULATIVOS EM ÁREAS EXTERIORES ÀS ÁREAS EDIFICADAS}

Com o objetivo de criar celeremente solos para a construção de habitações, foi introduzida a possibilidade de elaboração de planos vinculativos em áreas exteriores ao perímetro urbano através de um procedimento acelerado. $\mathrm{O}$ procedimento acelerado tem as

48 Deutsches Institut für Urbanistik, Instituto Alemão para Urbanistik, cliente: Bundesinstitut für Bau-, Stadt- und Raumforschung, Instituto Federal para a investigação referente a construção, a cidade e ao espaço: Planspiel zur Städtebaurechtsnovelle 2016/2017, Teste prático da aplicação do projeto de lei a casos concretos através da administração e outros participantes envolvidos, no total observaram representantes de seis municípios 30 exemplos, 31.1.2017, p. 89.

${ }^{49} \mathrm{O}$ já referido artigo 34 , do CFU (Innenbereich).

${ }^{50}$ Artigo 35, do CFU (Aussenbereich).

${ }^{51}$ Artigo 35, n.o 1, do CFU: "Im Aussenbereich ist ein Vorhaben nur zulässig, wenn öffentliche Belange nicht entgegenstehen, die ausreichende Erschliessung gesichert ist und wenn es 1. Einem land-oder forstwirtschaftlichen Betrieb dient und nur einen untergeordneten Teil der Betriebsfläche einnimmt, 2...".

${ }^{52}$ Nomeadamente os princípios dos artigos 1 e 1, alínea a, do CFU. 
seguintes características negativas: não exige participação pública prévia, não exige participação das outras entidades públicas envolvidas, não exige avaliação ambiental, não exige compensação ecológica e não exige o desenvolvimento do plano vinculativo a partir de um plano preparatório. ${ }^{53} \mathrm{~A}$ área do plano vinculativo aprovado pelo procedimento acelerado não pode ascender os $10.000 \mathrm{~m}^{2}$, e deve situar-se imediatamente na continuidade de áreas já edificadas ${ }^{54}$. O uso previsto no plano tem de ser a habitação. Como já referido, este novo instrumento caducará em 31 de dezembro de 2019.

Apesar da já citada experiência com algumas câmaras municipais, que participaram no teste prático do projeto-lei, demonstrar que a elaboração de um plano vinculativo pelo procedimento acelerado economiza, em média, vinte e duas semanas em face do procedimento ordinário, ${ }^{55}$ outras autarquias duvidam das virtudes dessa demonstração $0^{56} .57$

O novo instrumento é uma resposta à pressão política sobre questões relativas ao desenvolvimento de áreas contíguas às zonas edificadas no seu conjunto, ${ }^{58}$ e procura contribuir para ultrapassar a carência de 350.000 a 400.000 habitações, de acordo com estudos do Governo Federal Alemão. ${ }^{59}$

\footnotetext{
${ }^{53}$ Novo artigo 13, al. b, do CFU: inclusão de áreas exteriores ao perímetro urbano no procedimento acelerado - Até ao dia 31 de dezembro de 2019 aplica-se o artigo 13, al. a de forma análoga para planos vinculativos com uma área no sentido do artigo 13, al. a, n.o 1, frase 2, e com menos de 10.000 metros quadrados, e que determina a admissibilidade do uso da habitação em áreas que se situam junto as áreas edificadas no seu conjunto. O procedimento para a elaboração de um plano vinculativo no sentido da frase anterior pode ser introduzido formalmente apenas até ao dia 31 de dezembro de 2019; a aprovação do regulamento segundo o artigo 10, n.o 1 deve ser feita até ao dia 31 de dezembro de 2021. ("Einbeziehung von Aussenbereichsflächen in das beschleunigte Verfahren - Bis zum 31. Dezember 2019 bilt § 13므 entsprechend für Bebauungspläne mit einer Grundfläche im Sinne des $\S 13$ a Absatz 1 Satz 2 von weniger als 10000 Quadratmetern, durch die die Zulässigkeit von Wohnnutzungen auf Flächen begründet wird, die sich na im Zusammenhang bebaute Ortsteile anschliessen. Das Verfahren zur Aufstellung eines Bebauungsplans nach Satz 1 kann nur bis zum 31. Dezember 2019 förmlich eingeleitet werden; der Satzungsbeschluss nach § 10 Absatz 1 ist bis zum 31. Dezember 2021 zu fassen.")

${ }^{54}$ seja áreas no interior às áreas edificadas no sentido do artigo 34, do CFU, ou áreas edificadas e sujeitas a um plano vinculativo no sentido do artigo 30 , do CFU

${ }^{55}$ Assim representantes das câmaras de Leipzig e Bamberg.

${ }^{56}$ Assim representantes da câmara de Tübingen.

57 Deutsches Institut für Urbanistik, Instituto Alemão para Urbanística, cliente: Bundesinstitut für Bau-, Stadt- und Raumforschung, Instituto Federal para a investigação referente a construção, a cidade e aos espaços: Planspiel zur Städtebaurechtsnovelle 2016/2017, Teste prático da aplicação do projeto de lei a casos concretos através da administração e outros participantes envolvidos, no total observaram representantes de seis municípios 30 exemplos, 31.1.2017, p. 76.

${ }^{58}$ STEINKE, Michael/ZEMKE, Reinhold, Stadt/Ökonomie/Recht, Cidade/ Economia/Direito, Kommentar zur Städtebaurechtsnovelle 2017, Anotações a Reforma do Direito do Urbanismo 2017, Zu den Änderungen des BauGB und der BauNVO, Acerca das alterações do CFU e do RUGC, 16 de maio de 2017, http://stadtoekonomie-recht.de/\%c2\%a7-kommentar/kommentar-zur-staedtebaurechtsnovelle-2017/

${ }^{59} \mathrm{E}$ isto ainda sem contar com as necessidades dos refugiados e requerentes de asilo, Deutsche Bundesregierung, Governo Federal Alemão, Zusammenleben in der Stadt - Neue Spielräume für den
} 
A principal crítica em relação ao novo instrumento é a utilização e transformação facilitada de solos rústicos, até por que se encontra enraizado no CFU o princípio do reaproveitamento de solos já edificados em detrimento de novas urbanizações. ${ }^{60}$

\section{O procedimento acelerado no sentido do artigo 13 e 13, alínea a, do CFU}

“A pretensão de simplificar e acelerar os procedimentos anteriores à implementação de projetos é antiga, tendo levado a alterações legislativas sob a regência de todas as cores políticas." ${ }^{\prime 1}$ Assim, no âmbito das alterações e ampliações introduzidas ao procedimento acelerado da elaboração ${ }^{62}$ e alteração ${ }^{63}$ de planos preparatórios ${ }^{64}$ e vinculativos, os objectivos apresentados foram a promoção da construção de habitações e o melhor aproveitamento de áreas interiores ao perímetro urbano em detrimento da consumpção de solos rústicos. ${ }^{65} \mathrm{Na}$ vigência da Lei das Medidas referentes ao CFU ${ }^{66}$ entre 1990 e 1998, podiam as câmaras aplicar o

Wohnungsbau, Convívio na cidade - Mais espaço de manobra para a construção de habitações, 12 de abril de 2017, https://www.bundesregierung.de/Content/DE/Artikel/2016/11/2016-11-30-urbanegebiete.html; $\quad$ http://www.bayern.de/bundestag-greift-bayerns-forderungen-fuer-novelle-desbaugesetzbuches-auf/

60 Naturschutzbund Deutschland (NABU), Federação para a Proteção da Natureza, NABU-Stellungnahme zur Novellierung des BauGB, Gesetzentwurf der Bundesregierung vom 23. Januar 2017 (Drucksache 18/10942), Posicionamento da NABU referente a Reforma do Código Federal do Urbanismo, Proposta de lei do Governo Federal Alemão, de 23 de janeiro de 2017 https://www.nabu.de/imperia/md/content/nabude/nachbarnatur/170206_nabu-baugbnovelle_stellungnahme-.pdf

61 Bothe, Anja / Jorge, Maria do Rosário, Instrumentos novos para responder a desafios antigos de articulação no ordenamento do território - estudo das recentes reformas na legislação para o desenvolvimento espacial na Alemanha", in Revista do CEDOUA, n.o 35, 2015, ano XVIII_1.15, 1/22, p. 9, 27.

62 Desde 2004 constitui a segunda alternativa do n. 1 do artigo 13, do CFU, mas sem intenções do estabelecimento de novos direitos de usos urbanísticos, antes para a aprovação de planos de modo a evitar um determinado desenvolvimento, ou/e esclarecer a exclusão de determinados desenvolvimentos, assim Krautzberger, Michael, in Ernst, Werner/ Zinkahn, Willy/ Bielenberg, Walter/ Krautzberger, Michael: Baugesetzbuch - Código Federal do Urbanismo anotado, Beck, 124ㅇs suplemento, 2017, § 13, anotação 28a; desde 2007 previsto no artigo 13, al. a, do CFU para fins do desenvolvimento de áreas já urbanizadas.

63 Os casos clássicos do artigo 13, n. 1, do CFU referem-se as alterações e acrescentos de planos urbanísticos.

64 Planos preparatórios apenas podem ser alterados com base no artigo 13, não no artigo 13 alínea a, do CFU.

65 Assim nomeadamente pelas reformas de 1990, 2007 (introdução do artigo 13 alínea a), e 2013, cfr. Krautzberger, Michael in Ernst, Werner/ Zinkahn, Willy/ Bielenberg, Walter/ Krautzberger, Michael: Baugesetzbuch - Código Federal do Urbanismo anotado, Beck, 124o suplemento, 2017, § 13, anotações 4 - 14, anterior ao $\S 13$ a, anotação 5, § 13 a anotações 1 - 5 .

66 Baugesetzbuch-Massnahmengesetz, $\S 2$, n. 1 e 7 esta parte da lei (BauGBMassnG) é constituída pelos Artigos 1 e 2, da Lei para Facilitar a Construção de Habitações no Direito do Planeamento e da Construção e das alterações de Normas do Direito do Arrendamento, Gesetz zur Erleichterung des Wohnungsbaus im 
procedimento acelerado, mesmo quando eram afetadas as bases do planeamento, desde que o plano servisse para a promoção da construção de habitações. ${ }^{67} \mathrm{O}$ destaque da prioridade do desenvolvimento de zonas já urbanizadas para poupança de solos ainda permeáveis refletiu-se ainda nas reformas de $2007^{68}$ e $2013^{69}$ - nestas, o planeamento e a construção foram facilitados quando se tratava de empreendimentos que reutilizavam ou densificavam áreas onde já existia urbanização e edificação, ou que promoviam outros projetos de desenvolvimento de áreas já edificadas no seu conjunto. ${ }^{70}$

\section{Objetivo do desenvolvimento de zonas já edificadas e o princípio da poupança de solos}

Era já ambição assumida na Carta de Leipzig ${ }^{71}$, entre outros documentos políticos e legislativos, promover instrumentos para o desenvolvimento das áreas edificadas. Após a sua implementação, o Governo Alemão declarou, entre outros, o objetivo da diminuição da consumpção de solos rústicos ${ }^{72}$ para 30 hectares diários até 2030; em 2014 a média diária era

Planungs- und Baurecht sowie zur Änderung mietrechtlicher Vorschriften (WohnungsbauErleichterungsgesetz - WoBauErIG), de 17 de maio de 1990, in Boletim Oficial Federal (BGBI. I S. 926), http://www.stadtgrenze.de/s/bbg/1990/baugb-massnahmeng-1990.htm

67 Desde 1998 reza o artigo 13, n.o 1, do CFU outra vez: Desde que pela alteração ou pelo complemento feito por um plano urbanístico não sejam afetadas as bases do planeamento,...

68 Deutscher Bundestag, Parlamento Federal Alemão, Gesetz zur Erleichterung von Planungsvorhaben für die Innenentwicklung der Städte, Lei para facilitar projetos de planeamento para o desenvolvimento de zonas já urbanizadas das cidades, de 21 de dezembro de 2006, BGBI. I S. 3316; http://www.krautzberger.info/assets/2012/03/BauGB-Novelle_2007.pdf, http://dip21.bundestag.de/dip21/btd/16/024/1602496.pdf

69 Deutscher Bundestag, Parlamento Federal Alemão, Gesetz zur Stärkung der Innenentwicklung in den Städten und Gemeinden und weiteren Fortentwicklung des Städtebaurechts, Reforma para o desenvolvimento das áreas interiores ao perímetro urbano e do demais desenvolvimento do Direito do Urbanismo, de 11 de junho de 2013 - Innenenwicklungsnovelle, Boletim Oficial Federal, BGBI. 2013 I, N.은 29, $\quad$ p. $1548 \quad-\quad 1552$, https://www.bgbl.de/xaver/bgbl/start.xav\#_bgbl_\%2F\%2F*\%5B\%40attr_id\%3D\%27bgbl113s1548.pdf $\% 27 \% 5$ __ 1506089434163

70 Deutscher Bundestag, Parlamento Federal Alemão, Referência 17/11468, de 14 de novembro de 2012, Gesetzentwurf der Bundesregierung, Entwurf eines Gesetzes zur Stärkung der Innenentwicklung in den Städten und Gemeinden und weiteren Fortentwicklung des Städtebaurechts, Proposta de Lei do Governo Federal Alemão, na parte da fundamentação da nova lei: p. 9 http://dipbt.bundestag.de/doc/btd/17/114/1711468.pdf

${ }^{71}$ Ministros da UE responsáveis pela Política de Coesão, pela Coesão Territorial e Assuntos Urbanos, Carta sobre Cidades Europeias Sustentáveis, adotada na reunião informal dos ministros responsáveis pelo desenvolvimento urbano e coesão territorial da União Europeia em 2007, http://www.forumdascidades.pt/?q=content/carta-de-leipzig-2007;

http://www.bmub.bund.de/fileadmin/Daten_BMU/Download_PDF/Nationale_Stadtentwicklung/leipzig_c harta_en_bf.pdf

72 i.e., transformação de solos naturais em solos urbanizáveis e urbanizados. 
de 69 hectares, e em 2001 de 120 hectares. ${ }^{73}$

"Com solo e terra deve-se lidar de forma moderada, preservando-os; neste sentido, e no sentido da diminuição da consumpção adicional de áreas para o uso de edificações, devem ser aproveitadas as possibilidades do desenvolvimento do município, nomeadamente da requalificação dos terrenos de modo a reutilizá-los, através de um reforço da densificação, e através de outras medidas do desenvolvimento das áreas já consolidadas, devendo-se limitar a um grau necessário a permeabilização do solo." (Artigo 1 al. a, n. 2, do CFU) ${ }^{74}$

O CFU concretizava assim a cláusula de poupança do solo, transpondo a diretiva europeia relativa à avaliação dos efeitos de determinados planos e programas no ambiente. ${ }^{75}$ Esta reforma de 2004 contribuiu igualmente para a introdução da avaliação ambiental no planeamento urbanístico. ${ }^{76}$ Já em 1986 foram introduzidas as obrigações de poupar os solos e de salvar as áreas exteriores ao perímetro urbano. ${ }^{77}$

\section{Relação entre as alíneas a) e b) do artigo 13 do CFU}

O instrumento de procedimento acelerado para a elaboração de planos urbanísticos para áreas já urbanizadas prossegue os princípios aplicados à poupança dos solos: quando se visa o aproveitamento de zonas já edificadas, privilegia-se o planeamento e a construção, isentando, ao mesmo tempo, o procedimento de algumas exigências. No entanto, na reforma

73 Governo Federal Alemão, Estratégia de sustentabilidade para a Alemanha, 2016, p. 159, https://www.bundesregierung.de/Content/DE/_Anlagen/Nachhaltigkeit-wiederhergestellt/2017-01-11nachhaltigkeitsstrategie.pdf?_blob=publicationFile\&v=20

${ }^{74}$ Artigo 1 al. a, n.o 2, do CFU: "Mit Grund und Boden soll sparsam und schonend umgegangen werden; dabei sind zur Verringerung der zusätzlichen Inanspruchnahme von Flächen für bauliche Nutzungen die Möglichkeiten der Entwicklung der Gemeinde insbesondere durch Wiedernutzbarmachung von Flächen, Nachverdichtung und andere Massnahmen zur Innenentwicklung zu nutzen sowie die Bodenversiegelung auf das notwendige Mass zu begrenzen."

75 Deutscher Bundestag, Parlamento Federal Alemão, Gesetz zur Anpassung des Baugesetzbuchs an EURichtlinien (Europarechtsanpassungsgesetz Bau - EAG Bau), de 24 junho de 2004, Boletim Oficial Federal, BGBI. I, S. 1359, transpõe a Diretiva 2001/42/CE do Parlamento Europeu e do Conselho, de 27 de Junho de 2001, relativa à avaliação dos efeitos de determinados planos e programas no ambiente, https://www.bgbl.de/xaver/bgbl/start.xav?startbk=Bundesanzeiger_BGBI\&start=//*[@attr_id=\%27bgbl10 4s1359.pdf\%27]\#_bgbl_\%2F\%2F*\%5B\%40attr_id\%3D\%27bgbl104s1359.pdf\%27\%5D_150533838242 5; https://difu.de/publikationen/difu-berichte-32004/neue-anforderungen-an-die-bauleitplanung-durchdas.html

${ }^{76}$ Assim o artigo 2, n.o 4, frase 1, do CFU: Tendo em conta as necessidades da proteção ambiental conforme artigo 1, n. 6, ponto 7, e artigo 1, alínea a, é realizada uma avaliação ambiental, na qual devem ser identificados os impactos previsivelmente relevantes para o ambiente, devendo ser descritos e avaliados num relatório ambiental;" e a inserção nas prioridades do planeamento urbanístico: artigo 1 , n.. 6, ponto 7, do CFU: "as necessidades da proteção ambiental, inclusive da proteção da natureza e da paisagem, nomeadamente...". Um precursor destes instrumentos existia já desde 2001.

77 Artigo 35, n.․ 5, do CFU. 
de 2017, reconheceu-se tal privilégio ao planeamento e construção em zonas rurais, i.e., sempre que a autarquia pretende utilizar solos rústicos. As críticas à nova redacção do artigo 13, alínea b) do $\mathrm{CFU}^{78}$ incidem precisamente sobre esta aparente contradição: se, por um lado, o discurso público dos agentes políticos declara sistematicamente a intenção de obviar à urbanização dos solos naturais e rústicos, por outro lado, legislativamente, é privilegiada a aceleração de procedimentos sobre a urbanização de solos naturais.

Assim, para além da rejeição integral do procedimento acelerado para o planeamento de solos rústicos, sugerem-se constrangimentos ao âmbito de aplicação daquele novo instrumento, formulando-se os seguintes requisitos:

1. o plano visará a satisfação da necessidade urgente de oferta de habitação, ${ }^{79}$ ou

2. o plano limitar-se-á ao uso de habitações para refugiados ou para habitação social, ${ }^{80}$ ou

3. a sua aplicabilidade passa a depender da existência de um conceito local de desenvolvimento da habitação, ${ }^{81}$ ou

4. a sua aplicabilidade passa a depender da demonstração prévia da ausência de espaços para fins habitacionais, e apenas no interior do perímetro urbano, ${ }^{82}$ ou

5. o plano apenas se aplica a áreas consideradas exteriores ao perímetro urbano, que, no entanto, se situam "num contexto de urbanizações"83.

${ }^{78}$ UVP-Gesellschaft, Associação para a avaliação ambiental, Paukenschlag durch überarbeiteten Entwurf der BauGB-Novelle - Stellungnahme der UVP-Gesellschaft, Timpani através da proposta revista da reforma do Código Federal do Urbanismo - Posicionamento da Associação para a avaliação ambiental, 2017, http://www.uvp.de/de/uvp-recht/77-rechtsprechnung/887-stellungnahme-der-uvp-gesellschaft; Naturschutzbund Deutschland (NABU), Federação para a Proteção da Natureza, NABU-Stellungnahme zur Novellierung des BauGB, Gesetzentwurf der Bundesregierung vom 23. Januar 2017 (Drucksache 18/10942), Posicionamento da NABU referente a Reforma do Código Federal do Urbanismo, Proposta de lei do Governo Federal Alemão, de 23 de janeiro de 2017, p. 5 https://www.nabu.de/imperia/md/content/nabude/nachbarnatur/170206_nabu-baugbnovelle_stellungnahme-.pdf.

${ }^{79}$ Assim as Câmaras de Leipzig e Tübingen in Deutsches Institut für Urbanistik, Instituto Alemão para Urbanística, cliente: Bundesinstitut für Bau-, Stadt- und Raumforschung, Instituto Federal para a investigação referente a construção, a cidade e aos espaços: Planspiel zur Städtebaurechtsnovelle 2016/2017, Teste prático da aplicação do projeto de lei a casos concretos através da administração e outros participantes envolvidos, no total observaram representantes de seis municípios 30 exemplos, 31.1.2017, p. 76.

${ }^{80}$ Assim os representantes da câmara de Tübingen.

${ }^{81}$ Assim os representantes da câmara de Sylt.

82 Deutscher Bundestag, Parlamento Federal Alemão, Einbeziehung von Aussenbereichsflächen in das beschleunigte Verfahren, Inclusão de áreas exteriores ao perímetro urbano no procedimento acelerado, Referência WD 7 - 3000 - 001/17, de 17 de janeiro de 2017, p. 10, https://www.bundestag.de/blob/496940/fd90db88ec19bee622321eaa69dd5c9f/wd-7-001-17-pdfdata.pdf

${ }^{83}$ Áreas exteriores ao perímetro urbano dentro da área interior ao perímetro urbano, Aussenbereiche im Innenbereich; desenvolvimento de áreas exteriores ao perímetro urbano mas dentro do contexto de 
Relativamente a este último ponto, resolver-se-ia o problema com a introdução da respectiva alteração na alínea a) do artigo 13ㅇ do CFU. Exemplificando tal aplicação indica-se a conversão de áreas de uso militar para uso habitacional, ou de outras zonas que tem a qualificação de área rural, mas que se inserem em zonas já com certa edificabilidade ${ }^{84} .85$

Além do mais, acrescem dúvidas interpretativas sobre este novo instrumento, assim como à sua relação com o procedimento acelerado para o planeamento de áreas já urbanizadas $^{86}$. Desde logo, são pouco claros os termos aplicáveis a um planeamento que abranja simultaneamente áreas no interior e no exterior do perímetro urbano; assim, na elaboração desse plano, devem aplicar-se as exigências constantes da alínea a) ou da alínea b) $?^{87}$

Recordamos que, em 2015, o Tribunal Federal Administrativo decidiu que não era admissível incluir áreas exteriores ao perímetro urbano num planeamento acelerado fundamentado na alínea a) do artigo $13^{\circ}$ do CFU.88 Impõe-se, portanto, uma clara delimitação entre a aplicação do planeamento acelerado para zonas externas e internas especialmente para conservar e observar os limites máximos da extensão das zonas já urbanizadas $\left(20.000 \mathrm{~m}^{2}\right)^{89} \mathrm{e}$ das zonas exteriores ${ }^{90} 91\left(10.000 \mathrm{~m}^{2}\right)$.

Assim, propõe-se a possibilidade de combinação do planeamento acelerado para, simultaneamente, as zonas exteriores e interiores ao perímetro urbano, sendo que, quanto aos limites máximos de extensão, se aplique, para as áreas externas, a referida alínea b) do artigo 13 do CFU, e, para o conjunto das áreas externas e internas, os limites máximos da alínea a).

Deparamo-nos, igualmente, com falta de clareza no que respeita ao pressuposto do uso habitacional para o planeamento acelerado. Na verdade, questionamo-nos se o novo

áreas edificadas no seu conjunto, no sentido de uma densificação, Entwicklung von Aussenbereichsflächen, die sich in einem Siedlungszusammenhang befinden, und zwar im Sinne einer Verdichtung.

${ }^{84}$ Assim os representantes da câmara de Bamberg, p. 76

${ }^{85}$ Assim os representantes das câmaras que participaram no teste prático do projeto da legislação nova in Deutsches Institut für Urbanistik, Instituto Alemão para Urbanística, cliente: Bundesinstitut für Bau-, Stadt- und Raumforschung, Instituto Federal para a investigação referente a construção, a cidade e aos espaços: Planspiel zur Städtebaurechtsnovelle 2016/2017, Teste prático da aplicação do projeto de lei, 2017, p.72 e ss.

${ }^{86}$ Artigo 13, alínea a, do CFU.

${ }^{87}$ Assim os representantes da câmara de Leipzig, p. 73, 80.

${ }^{88}$ Bundesverwaltungsgericht, Tribunal Federal Administrativo, BVerwG 4 CN 9.14, de 4 de novembro de 2015, http://www.bverwg.de/entscheidungen/entscheidung.php?ent=041115U4CN9.14.0

${ }^{89}$ Artigo 13, al. a, do CFU.

${ }^{90}$ Artigo 13, al. b, do CFU.

${ }^{91}$ Assim os representantes da câmara de Leipzig, p. 81. 
instrumento se reporta também aos usos relacionados com a habitação, v.g. o planeamento de uma creche ou de um centro de dia..$^{92}$

\section{Distinção entre procedimento ordinário e procedimento acelerado}

No procedimento acelerado, as câmaras municipais podem ${ }^{93}$ determinar a isenção da exigência de participação prévia do público, de participação das entidades públicas afectadas pelo plano, ${ }^{94}$ além da avaliação ambiental, ${ }^{95}$ da compensação ecológica, ${ }^{96}$ e da exigência de se desenvolver o plano vinculativo a partir do plano preparatório ${ }^{97}$.

Como já referido, este novo instrumento tem merecido a ampla concordância das entidades públicas relativamente ao planeamento da construção de habitações necessárias. ${ }^{98}$ No entanto, por ainda se propor a rejeição daquele, ${ }^{99}$ entendemos necessário analisar, de forma mais detalhada, os fundamentos para tal proposta. ${ }^{100}$

\section{Participação pública prévia}

Nos termos do procedimento ordinário, deve ser garantido a participação prévia do

\footnotetext{
92 Assim os representantes das câmaras de Colonia e Leipzig, p. 73, 78, 79.

93 Insere-se no poder discricionário da câmara conforme o artigo 1, n. 3, do CFU e do artigo 28, n.․ 2 da Constituição Federal da Alemanha (Direito à autonomia do poder local) se é aplicado o procedimento ordinário, i.e., os artigos 2. a 4.ํ, al. c, do CFU, ou o procedimento acelerado; o requerente da autorização de um projeto não tem nenhum direito à aplicação do procedimento acelerado, cfr. Krautzberger, Michael in Ernst, Werner/ Zinkahn, Willy/ Bielenberg, Walter/ Krautzberger, Michael: Baugesetzbuch - Código Federal do Urbanismo anotado, Beck, 124ㅇcomplement, 2017, artigo 13, a, anotação 13.

${ }^{94}$ Artigos 13, al. a, n.o 2, e 13, n. -2 , do CFU.

${ }^{95}$ Artigos 13, al. a, n.o 2, e 13, n.o 3, do CFU.

${ }^{96}$ Artigo 13, al. b juntamente com o artigo 13, al. a, n.o 2, ponto 2, do CFU.

${ }^{97}$ Exceção em relação ao artigo 8, n.o 2, do CFU e prevista no novo artigo 13, alínea b, do CFU.

${ }^{98}$ Apenas neste sentido temporal: os representantes das câmaras de Colonia, Sylt, Leipzig e Tübingen, p. 76, 77.

99 Battis, Ulrich/ Mitschang, Stephan/ Reidt, Olaf, Das Gesetz zur Umsetzung der Richtlinie 2014/52/EU im Städtebaurecht und zur Stärkung des neuen Zusammenlebens in der Stadt (BauGB-Novelle 2017), A lei da transposição da Diretiva 2014/52/UE no Direito do Urbanismo e para o reforço do novo tipo de convívio na cidade (Reforma do Código Federal do Urbanismo 2017), NVwZ Revista Nova da Administração, 2017, p. 817,820 .

100 Deutsches Institut für Urbanistik, Instituto Alemão para Urbanística, cliente da elaboração do estudo: Bundesinstitut für Bau-, Stadt- und Raumforschung, Instituto Federal para a investigação referente a construção, a cidade e aos espaço: Planspiel zur Städtebaurechtsnovelle 2016/2017, Teste prático da aplicação do projeto de lei a casos concretos através da administração e outros participantes envolvidos, no total observaram representantes de seis municípios 30 exemplos, 31.1.2017, p. 76 e ss., https://difu.de/publikationen/2017/planspiel-zur-staedtebaurechtsnovelle-2016-2017.html
} 
público ${ }^{101}$ e das autoridades, nomeadamente, da repartição de finanças, da protecção da natureza, da recolha de resíduos, da saúde e do ensino, dos transportes e dos equipamentos colectivos, etc., cujas competências incidam sobre áreas afetadas pelo plano em elaboração ${ }^{102}$. Pretende-se, desse modo, garantir: a implementação de princípios democráticos, a informação das autoridades acerca dos interesses a acautelar com o planeamento, e a determinação dos conteúdos e do grau de pormenorização da avaliação ambiental - o scoping. Esta participação tem de ocorrer necessariamente numa fase anterior à decisão sobre pontos fulcrais do planeamento e, eventualmente, numa fase anterior ao início do processo formal de planeamento.

O conceito de público abrange todos os que possam ter ou alegar ter um interesse legítimo ou um direito que pode ser afectado pelo plano em questão. Assim, o público e as já referidas autoridades têm de ser instruídos sobre a configuração e o alcance do plano em questão, nomeadamente, as suas alternativas e principais implicações.

Assim, a câmara municipal pode não realizar esta participação pública prévia quando aplica o novo instrumento do procedimento acelerado à elaboração de planos vinculativos em áreas exteriores ao perímetro urbano. ${ }^{103}$ Ao tornar facultativa a participação prévia, de modo a simplificar e acelerar todo o procedimento, tal não significa a definitiva exclusão do público e das entidades públicas envolvidas nesse procedimento. Na verdade, quer o público, quer as autoridades afetadas, têm sempre direito à uma participação sucessiva. ${ }^{104}$

O legislador formulou duas situações alternativas para a obrigatoriedade de participação sucessiva, ou após ter sido dado acesso às informações pertinentes ao planeamento, ou quando vier a ser aplicado o instrumento da participação pública sucessiva. ${ }^{105}$ Teleologicamente, nos dois casos estamos perante a mesma situação: tem de ser dado acesso, durante um período adequada, às informações pertinentes sobre o impacto do plano, e tem de ser criada oportunidade ao público e às autoridades de exporem as suas preocupações quanto ao plano. Se tais exposições devem ser avaliadas e julgadas pelas câmaras municipais, ainda assim, estas não estão vinculadas à aceitação das críticas elaboradas, podendo, como é evidente, invocar interesses e valores distintos na sua tutela.

No teste prático da aplicação do projeto de legislação, apenas os representantes de

\footnotetext{
${ }^{101}$ Artigo 3, n.ㅇ 1, do CFU.

102 Artigo 4, n.o 1, do CFU.

${ }^{103}$ Artigo 13, al. b, do CFU.

104 Artigo 13, n. 2, ponto 2 e 3, do CFU.

105 No sentido dos artigos 3 e 4, do CFU.
} 
uma autarquia consideraram importante a nova prerrogativa legal da exclusão da participação prévia. ${ }^{106}$ Como já acima referido, vários representantes de outras autarquias desmereceram a vantagem, rejeitando, inclusive, a sua possibilidade, de qualquer poupança de tempo através da exclusão da participação prévia, especialmente porque, constituindo as áreas situadas juntas a áreas já edificadas espaços de grande interesse público, ${ }^{107}$ irá sempre alegar-se posteriormente a falta de transparência no planeamento, além da inevitável depreciação da qualidade de vida dos moradores com a diminuição de espaços verdes importantes. Este protesto posterior implicará maiores atrasos no procedimento do que todos os ganhos de tempo com a isenção da participação pública prévia. ${ }^{108}$ Recordamos precisamente que, quando foi introduzida a participação prévia, uma das suas finalidades era evitar protestos numa fase posterior do planeamento, quando os planos e projetos já se encontram de tal forma consolidados que se torna mais difícil não só alterá-los, como obter uma eventual concordância da população. ${ }^{109}$

\section{Avaliação ambiental e Direito da União Europeia}

Numa primeira fase, a avaliação ambiental visava apenas a análise dos impactos ambientais de projetos. ${ }^{110}$ Posteriormente, acrescentou-se a avaliação ambiental estratégica, ${ }^{111}$ instrumento preventivo que visa acautelar impactos negativos no ambiente. ${ }^{112}$ As suas principais vantagens residem no aprofundamento do princípio da transparência, e na avaliação consciente de efeitos previsíveis e conjunturas configuráveis. ${ }^{113}$

\footnotetext{
${ }^{106}$ Assim os representantes da câmara de Leipzig, p. 76.

107 Porque os moradores dão um uso público aos espaços que não querem perder. Para além disto, também se revoltarão contra a retirada de áreas verdes sem obrigação da compensação por parte dos investidores, p. 77.

${ }^{108}$ Assim os representantes das câmaras de Colonia, Tübingen, Bamberg, Sylt, p. 77, 78.

$109 \mathrm{Cfr}$. Bothe, Anja, German law covering the public participation in planning and building infrastructure projects, in Albertina Dias, Bror Salmelin, David Pereira, Miguel Sales Dias, Modelling Innovation Sustainability and Technologies, Editora Springer, 2016 - (capítulo em livro sobre conferência em Oeiras, 22, 23 de Outubro de 2015), p. 8

110 Diretiva 85/337/CEE, de 27 de junho de 1985 alterada pela Diretiva 97/11/CE, pela Diretiva 2009/31/CE, e pela Diretiva 2011/92/UE, de 13 de dezembro de 2011, relativa à avaliação dos efeitos de determinados projetos públicos e privados no ambiente (codificação), http://eur-lex.europa.eu/legalcontent/PT/TXT/HTML/?uri=LEGISSUM:ev0032\&from=PT

111 Diretiva 2001/42/CE, de 27 de junho de 2001, relativa à avaliação dos efeitos de determinados planos e programas no ambiente, Jornal Oficial no L 197 de 21/07/2001 p. 0030 - 0037, http://eurlex.europa.eu/legal-content/PT/TXT/HTML/?uri=CELEX:32001L0042\&from=PT

112 Como se trata de um instrumento meramente procedimental, a avaliação ambiental é criticada por apenas ter criado uma indústria da sua aplicação (Environmental Assessment), mas não ter conseguido evitar projetos prejudiciais para o ambiente, Messerschmidt, Klaus, Europäisches Umweltrecht, Beck, p. 520.

${ }^{113}$ Epiney, Astrid, Umweltrecht der Europäischen Union, Nomos, 3a Ed., 2013, Baden-Baden, p. 317.
} 
A transposição do conceito de avaliação ambiental estratégica, numa fase precoce do planeamento, foi concretizada na Alemanha no Código Federal do Urbanismo através do instrumento de planeamento urbanístico. ${ }^{114}$ É precisamente a isenção da obrigatoriedade desta avaliação que a reforma de 2017 veio configurar, sendo, então, admitida nos planos urbanísticos em áreas exteriores ao perímetro urbano e no procedimento acelerado para fins habitacionais. ${ }^{115}$

Tornada facultativa a avaliação ambiental, as câmaras podem ainda não implementar os seguintes instrumentos: o relatório ambiental, ${ }^{116}$ a indicação das informações ambientais disponibilizadas no âmbito da participação pública, ${ }^{117}$ o resumo técnico sobre os interesses ambientais e os resultados da participação pública e das autoridades públicas, com a fundamentação das posições adoptadas ${ }^{118}$, e a auditoria do plano urbanístico em relação aos efeitos ambientais relevantes (monitoring) ${ }^{119}{ }^{120}$

Os opositores do novo instrumento alertam para a violação da Diretiva Europeia relativa à avaliação dos efeitos de determinados planos e programas no ambiente ${ }^{121}{ }^{122}$ Assim, quando foi introduzida a aplicação facultativa da avaliação ambiental nas áreas interiores ao perímetro urbano, considerou-se a mesma em conformidade com a referida Diretiva Europeia, porque os Estados-Membros podem excluir planos e programas em que se determine a utilização de pequenas áreas a nível local, e que não são suscetíveis de ter efeitos significativos no ambiente. ${ }^{123}$ Os propugnadores do novo instrumento consideram que a mesma fundamentação pode ser usada quanto a planos para as áreas exteriores ao perímetro urbano. ${ }^{124}$ No entanto,

\footnotetext{
114 Desde 2004, artigo 2, n. 4, CFU.

115 Artigo 13, al. b, do CFU.

116 No sentido do artigo 2, al. a, do CFU - Fundamentação da proposta do plano urbanístico e relatório ambiental.

${ }^{117}$ Artigo 2, n.o 2, frase 2, do CFU.

118 Artigo 10, n. 4 , do CFU.

119 Artigo 4.․ al. c, do CFU.

${ }^{120}$ Artigos 13, al. b, 13, n. o 3, do CFU.

${ }^{121}$ Diretiva 2001/42/CE, de 27 de junho de 2001.

122 Vereinigung für Stadt-, Regional- und Landesplanung (SDL); Bund Deutscher Landschaftsarchitekten (bdl), União para o Planeamento da Cidade, da Região e do Estado Federado, Federação dos Arquitetos Paisagistas, Stellungnahme der SRL und des bdla zur Einführung des $\S 13 b$ BauGB, Posicionamento da SRL e da bdla acerca da introdução do $\S$ 13, al. b, do CFU, motivo 11, 25 de janeiro 2017, http://www.srl.de/dateien/dokumente/de/Stellungnahme_BauGB2017_SRL_bdla.pdf

${ }^{123}$ Artigo 3.․ n.o 3, da Diretiva 2001/42/CE: "Os planos [...] em que se determine a utilização de pequenas áreas a nível local [...] só devem ser objecto de avaliação ambiental no caso de os Estados-Membros determinarem que os referidos planos e programas são suscetiveis de ter efeitos significativos no ambiente."

124 Que defende que os objetivos das necessidades urgentes de investimentos para a manutenção, segurança e criação de postos de trabalho, o fomento das populações com habitações e a realização de
} 
dado que os planos referentes às áreas rústicas são regularmente "...suscetíveis de ter efeitos significativos no ambiente", 125 o Conselho Federal pronunciou-se no sentido da existência de dúvidas relativamente à conformidade do novo instrumento com o Direito da União. ${ }^{126}$

De qualquer forma, as câmaras municipais têm um poder discricionário sobre a realização da avaliação ambiental. Este poder aplica-se também ao procedimento acelerado, se bem que sujeito à observação dos princípios e das prioridades legais do planeamento urbanístico, ${ }^{127}$ e das regras adicionais para a proteção do ambiente. ${ }^{128}$ No contexto da presente análise, tem destacada importância a obrigação de um desenvolvimento prioritário de áreas já urbanizadas em detrimento da urbanização de áreas rústicas. ${ }^{129}$

Relação do plano vinculativo com o plano preparatório

O imperativo respeito de princípios, orientações gerais e prioridades de todo o planeamento urbanístico $^{130}$ repete-se na análise da admissibilidade da elaboração acelerada do plano vinculativo com variação do plano preparatório: ${ }^{131}$ Ao admitir-se procedimento acelerado, ${ }^{132}$ rejeita-se sempre um instrumento que não observe as características principais e

infraestruturas "não poderão ser sacrificados à burocracia". Mas devem ser ponderados com as prioridades de um ambiente saudável de trabalhar e viver e dos interesses ambientais, Bundesverband Freier Immobilien- und Wohnungsunternehmen, União Federal de empresas independentes do setor imobiliário e da habitação, Mitglieder-Information, Informação para os membros, Bauplanungsrechtsnovelle aktuell, Atual: a reforma do Direito do Urbanismo, 4 de abril de 2017, https://www.bfw-bund.de/api/downloads/view/18781

${ }^{125}$ Artigo 3.o, n.o 3, da Diretiva 2001/42/CE.

126 Bundesrat, Conselho Federal, Referência 806/16 (Beschluss) Decisão, 10 de fevereiro de 2017 Stellungnahme des Bundesrates, Posicionamento do Conselho Federal, Entwurf eines Gesetzes zur Umsetzung der Richtlinie 2014/52/EU im Städtebaurecht und zur Stärkung des neuen Zusammenlebens in der Stadt, Posta de Lei para a transposição da Diretiva 2014/52/UE no Direito do Urbanismo e para reforçar o novo tipo de convívio na cidade, p. 8, 9, https://www.umweltonline.de/PDFBR/2016/0806_2D16B.pdf; assim também os representantes da câmara de Colónia no teste prático, p. 76.; defende que a avaliação ambiental é precisamente o momento criado para verificar se haverá ou não esta suscetibilidade do plano ter efeitos significativos no ambiente, Vereinigung für Stadt-, Regional- und Landesplanung (SRL); Bund Deutscher Landschaftsarchitekten (bdl), União para o Planeamento da Cidade, da Região e do Estado Federado, Federação dos Arquitetos Paisagistas, Stellungnahme der SRL und des bdla zur Einführung des $\S 13 b$ BauGB, Posicionamento da SRL e da bdla acerca da introdução do $\S$ 13, al. b, do CFU, motivo 11, 25 de janeiro 2017, motivo 5, http://www.srl.de/dateien/dokumente/de/Stellungnahme_BauGB2017_SRL_bdla.pdf.

${ }^{127}$ Artigo 1, n.ㅇs 5, 6, 7, do CFU.

128 Artigo 1, al. a, do CFU.

129 Desde 2013 destacado no artigo 1, n.o 5, frase 3, do CFU, e também no artigo 1, al. a, n. 2, do CFU (obrigação da poupança de solos).

130 Artigo 1, n.os 5, 6, 7, e artigo 1, al. a, do CFU.

131 Artigo 13, al. a, n.o 2, ponto 2, do CFU.

132 Seja no âmbito do artigo 13, al. a, ou al. b, do CFU. 
as exigências materiais essenciais do planeamento estabelecidas no Código Federal do Urbanismo ${ }^{133}{ }^{134}$

Para facilitar e simplificar a elaboração de um plano vinculativo em áreas exteriores ao perímetro urbano, o novo artigo 13, alínea b), do CFU, prescreve a possibilidade de o plano vinculativo se desviar do plano preparatório. Esta situação é excepcional. A norma reside na obrigatoriedade do plano vinculativo ser desenvolvido com base e em conformidade com o plano preparatório. ${ }^{135}$ Aplicando-se a exceção por motivos procedimentais, o plano preparatório passa a adaptar-se ao plano vinculativo estabelecido no processo acelerado.

Este aumento de flexibilidade, agora introduzido na alínea b) do artigo 13 do CFU, tem já antecedentes, ${ }^{136}$ que, em grande parte, ${ }^{137}$ têm o seu principal objetivo, tal como o novo instrumento de 2017, no planeamento acelerado de áreas para habitações.

Apesar da referida e indispensável observação das orientações básicas para todo o planeamento urbanístico, ${ }^{138}$ receia-se que o novo instrumento, ao admitir o afastamento do plano preparatório na elaboração acelerada de planos vinculativos para solos rústicos, ${ }^{139}$ traga consigo uma maior desvalorização do planeamento preparatório ${ }^{140} \mathrm{e}$, consequentemente, de

\footnotetext{
${ }^{133}$ Artigo 1, n.ㅇs 5, 6, 7, e artigo 1, al. a, do CFU.

134 Krautzberger, Michael in Ernst, Werner/Zinkahn, Willy/ Bielenberg, Walter/ Krautzberger, Michael, Baugesetzbuch - Código Federal do Urbanismo anotado, Beck, 124o suplemento, 2017, § 13 a, anotação 74.

${ }^{135}$ Artigo 8, n.o 2, do CFU.

${ }^{136}$ A exigência da observação do plano preparatório por parte do plano vinculativo foi sendo mitigada nas reformas do CFU de 1978, de 1986, de 1990, de 1993, cfr. Bothe, Anja, Vergleich des portugiesischen und deutschen Bauplanungs- und Sanierungsrechts im Hinblick auf die Zielsetzung einer sozial ausgeglichenen Wohnraumversorgung - Erfahrungen in den Metropolen Lissabon und Berlin, Instrumentos jurídicos de implementação do direito à habitação no direito do urbanismo alemão e português - experiências nas metrópoles Lisboa e Berlim, monografia, 323 p., Editora Lit, Münster, 2004, p. 125 e ss.

137 A alínea a do artigo 13, do CFU, foi introduzida, em 2007, com o objetivo do desenvolvimento prioritário de áreas internas do perímetro urbano, admitindo também um afastamento do plano preparatório, contrariando a regra geral do artigo 8, n. 2, do CFU.

${ }^{138}$ A presente análise discorda com a afirmação em Vereinigung für Stadt-, Regional- und Landesplanung (SRL); Bund Deutscher Landschaftsarchitekten (bdl), União para o Planeamento da Cidade, da Região e do Estado Federado, Federação dos Arquitetos Paisagistas, Stellungnahme der SRL und des bdla zur Einführung des § 13b BauGB, Posicionamento da SRL e da bdla acerca da introdução do § 13, al. b, do CFU, motivo 11, 25 de janeiro 2017, motivo 4, de que a dispensa da observação do plano preparatório no procedimento da elaboração acelerada leva a ausência da verificação da concordância do novo plano vinculativo com as exigências fundamentais do artigo 1, alíneas 5 a 7, e do artigo 1, alínea a, do CFU, que podem aqui ser resumidas como as principais preocupações da proteção da natureza, http://www.srl.de/dateien/dokumente/de/Stellungnahme_BauGB2017_SRL_bdla.pdf.

139 Artigo 13, al. b juntamente com o artigo 13, al. a, n.o 2, ponto 2, do CFU.

140 Battis, Ulrich/ Mitschang, Stephan/ Reidt, Olaf, Das Gesetz zur Umsetzung der Richtlinie 2014/52/EU im Städtebaurecht und zur Stärkung des neuen Zusammenlebens in der Stadt (BauGB-Novelle 2017), A lei da transposição da Diretiva 2014/52/UE no Direito do Urbanismo e para o reforço do novo tipo de convívio
} 
todo o planeamento urbanístico. ${ }^{141}$

Isenção da compensação ecológica

A mais grave consequência resultante da aplicação do procedimento acelerado em planos vinculativos referentes a áreas de solos rústicos será a isenção da compensação ecológica. ${ }^{142}$

Esta isenção havia sido inicialmente introduzida para o procedimento acelerado da elaboração de planos vinculativos para áreas já urbanizadas. Partia-se do princípio que o desenvolvimento de áreas urbanizadas não impunha a compensação ecológica, como a transformação de áreas ainda não urbanizadas. ${ }^{143}$ Surgia, assim, como uma exigência fundamental do Código Federal do Urbanismo e do Código Federal da Proteção da Natureza, a preocupação e prevenção de intervenções com impacto negativo na natureza entendendo-se que, caso não seja possível evitar tal impacto, deve ocorrer a devida compensação. ${ }^{144}$

No entanto, se tivermos em conta as elevadas despesas inerentes à reabilitação de áreas já urbanizadas e ao desenvolvimento de zonas já edificadas, ${ }^{145}$ a isenção da compensação ecológica em investimentos urbanísticos em solos rústicos, que já por si mesmos são menos dispendiosos, parece não só constituir um incentivo a tais investimentos, como um verdadeiro

na cidade (Reforma do Código Federal do Urbanismo 2017), NVwZ Revista Nova da Administração, 2017, p. 820.

${ }^{141}$ Assim os representantes da câmara de Bamberg, teste prático, p. 76; Vereinigung für Stadt-, Regionalund Landesplanung (SRL); Bund Deutscher Landschaftsarchitekten (bdl), União para o Planeamento da Cidade, da Região e do Estado Federado, Federação dos Arquitetos Paisagistas, Stellungnahme der SRL und des bdla zur Einführung des $\S 13 b$ BauGB, Posicionamento da SRL e da bdl referente a introdução do $\S 13$ al. b, do CFU, motivo 11, 25 de janeiro 2017, http://www.srl.de/dateien/dokumente/de/Stellungnahme_BauGB2017_SRL_bdla.pdf, motivo 4, considera uma intervenção inaceitável na cultura de planeamento e de construção na Alemanha.

142 Artigo 13, al. a, n. 2, ponto 4, juntamente com o artigo 1, al. a, n. 3, frase 6, do CFU; opinião contrária têm os representantes da câmara de Leipzig, chamando a atenção pelo fato de ambos os tipos de planos serem decididos pela mesma autarquia, e que os interesses a ponderar serão os mesmos, $\mathrm{p}$. 78.

${ }^{143}$ Deutscher Bundestag, Parlamento Federal Alemão, Referência 16/3308, de 8 de novembro de 2006, Beschlussempfehlung und Bericht des Ausschusses für Verkehr, Bau und Stadtentwicklung zu dem Gesetz der Bundesregierung - Drucksachen 16/2496, 16/2932 -, Aconselhamento em relação a deliberação e relatório da comissão para o trânsito, e o desenvolvimento da construção e da cidade em relação a Lei do Governo Federal - Referências 16/2496, 16/2932 -, $\quad$ p. 17, http://dipbt.bundestag.de/dip21/btd/16/033/1603308.pdf

144 Artigo 1, alínea a, n.o 3, frase 2 a 5, do CFU, Artigo 15, do Código Federal da Proteção da Natureza https://www.gesetze-im-internet.de/bnatschg_2009/_15.html.

${ }_{145}$ P. ex. despesas de demolição e eliminação de (partes de) construções, renovações de terrenos e (partes de) construções. 
prémio. ${ }^{146}$ Desse modo, restaria adulterada a concretização de um planeamento em prol da poupança de solos, dado que se concederia benefícios económicos a investimentos feitos com gastos de solos. ${ }^{147}$

Esta interpretação do novo instrumento afigura-se contradizer os princípios da legislação aplicável. Assim, quando se trata de planos referentes a áreas exteriores ao perímetro urbano, os requisitos de aplicação da referida isenção da compensação devem ser interpretados teleologicamente, verificando-se em cada caso se o plano promovido implica ou irá implicar uma intervenção negativa e relevante no ambiente. Perante uma resposta afirmativa, não se aceitará aplicar a isenção da compensação ecológica. ${ }^{148}$

\section{Caducidade do instrumento em 2019 - a sentimento de urgência}

A aplicação facultativa do procedimento acelerado, no qual a participação prévia, a avaliação ambiental, o desenvolvimento do plano vinculativo a partir do plano preparatório, e a compensação ecológica, irá caducar em 31 de dezembro de 2019. Apenas poderão ser realizados com a aplicação do novo instrumento ${ }^{149}$ os procedimentos de planos vinculativos, cuja elaboração tenha sido formalmente iniciada até essa data e a aprovação do plano 150 concluída até 31 de dezembro de 2021.

\footnotetext{
146 Representantes das câmaras de Colónia e de Sylt no teste prático, p. 76: o novo instrumento aumentará ainda mais a pressão para investimentos no exterior de perímetros urbanos, algo que as câmaras já sentem devido a maior abertura destes espaços desde a reforma que privilegia o planeamento e a construção de alojamentos de refugiados nas áreas externas ao perímetro urbano, Gesetz über Massnahmen zur Erleichterung der Unterbringung von Flüchtlingen, nomeadamente o artigo 246, n.s 9, 13, 14 juntamente com o artigo 35, n.․ 4, do CFU, que facilitam habitações e alojamentos para refugiados e requerentes de asilo nas áreas exteriores ao perímetro urbano, cfr. Krautzberger, Michael/ Stüer, Bernhard, BauGB-Novelle 2014 II: Erleichterte Unterbringung von Flüchtlingen, Reforma II do Código Federal do Urbanismo: Alojamento facilitado de refugiados, in DVBI Revista da Administração Alemã, 2, 2015, p. 73, 74, 76, http://www.stueer.business.t-online.de/aufsatzc/dvbl0215.pdf)

147 Também economicamente questionável, uma vez que se oferece uma disponibilidade de áreas a tarifa ecológica zero, e isto num período em que o setor imobiliário já se encontra aquecido demais por causa dos juros baixos para créditos de habitação, UVP-Gesellschaft, Paukenschlag durch überarbeiteten Entwurf der BauGB-Novelle - Stellungnahme der UVP-Gesellschaft, 2017.

148 Deutscher Bundestag, Gesetzentwurf der Bundesregierung - Entwurf eines Gesetzes zur Erleichterung von Planungsvorhaben für die Innenentwicklung der Städte, Proposta de lei do Governo Federal Proposta de lei para facilitar empreendimentos de planeamento para o desenvolvimento do interior do perímetro urbano, de 4 de setembro de 2006, Referência 16/2496, p. 15, http://dip21.bundestag.de/dip21/btd/16/024/1602496.pdf; Deutscher Bundestag, Parlamento Federal Alemão, Einbeziehung von Aussenbereichsflächen in as beschleunigte Verfahren, Inclusão de áreas exteriores ao perímetro urbano, Ref. WD 7- 3000-001/17, p. 8, https://www.bundestag.de/blob/496940/fd90db88ec19bee622321eaa69dd5c9f/wd-7-001-17-pdfdata.pdf.

${ }^{149}$ Artigo 13, al. b, frase 2, do CFU.

150 No sentido do artigo 10, n.o 1, do CFU: a autarquia aprova o plano em forma de regulamento.
} 
A limitação temporal deste instrumento demonstra claramente a específica pretensão de planear e construir mais habitações a curto prazo. Revela, igualmente, que o legislador tem plena consciência de certas desarmonias entre a abertura para construção das áreas exteriores ao perímetro urbano com as ambições da poupança de solos naturais, tal como com o objetivo prioritário do desenvolvimento de áreas já edificadas. Contudo, por outro lado, receia-se que tal limitação no tempo venha a causar um efeito de ávida necessidade nas câmaras e nos investidores que tentarão aproveitar esta oportunidade, deste modo criando condições para o gasto de solos naturais, sem as devidas carências em termos habitacionais. ${ }^{151}$

\section{CONCLUSÃO: PERIGO DE RETROCESSO DO ESTADO SOCIAL E ECOLÓGICO}

Os objetivos explicitados na reforma analisada refletem manifestamente a preocupação social de criar habitações economicamente acessíveis. No entanto, as alterações legais introduzidas para estes efeitos implicam compromissos que diminuem quer os níveis de proteção contra o ruído, quer os de proteção paisagística e ambiental. Na nova categoria de "área urbana", recordamos que se admite um grau mais elevado de ruído em zonas de habitação, que a isenção do requisito de inserção na envolvente se torna-se facultativa, apesar de constituir uma exigência do ordenamento do território, e que, com a opção do procedimento acelerado para o planeamento de áreas rústicas, se sacrifica a prioridade na poupança de solos naturais, há décadas enraizada na prática política. Apesar de se tratar de uma vontade do legislador de mostrar obra feita para ir ao encontro de uma necessidade básica da população que é a habitação, esta ambição, cujos contornos político-partidários não nos escapam, implica um claro retrocesso em termos urbanísticos na Alemanha.

\section{Propostas: gestor do desenvolvimento de áreas já urbanizadas}

Entendemos, no entanto, que um reforço da gestão ativa dos espaços já urbanizados seria muito mais produtivo na promoção do uso habitacional nas zonas já edificadas. Não devemos esquecer o potencial de zonas dentro das áreas já urbanizadas, que poderão ser

151 UVP-Gesellschaft, Associação para a avaliação ambiental, Paukenschlag durch überarbeiteten Entwurf der BauGB-Novelle - Stellungnahme der UVP-Gesellschaft, Timpani através da proposta revista da reforma do Código Federal do Urbanismo - Posicionamento da Associação para a avaliação ambiental, 2017, http://www.uvp.de/de/uvp-recht/77-rechtsprechnung/887-stellungnahme-der-uvp-gesellschaft, que relata que é o que se passou na introdução da avaliação estratégica devido a reforma de 2004, em que as câmaras procuraram criar solos urbanizáveis antes da entrada em vigor das exigências legais do novo instrumento de proteção ambiental. 
ativadas para o uso habitacional e que apenas não o são, tantas vezes, por motivos de especulação ou falta de investidores, ou por se ansiar por soluções mais fáceis. Procurar ativamente iniciativas no sentido da promoção da habitação cabe na função política do Estado em todos os níveis da sua organização, ainda que se queixe o poder local de falta de recursos para o efeito.

Assim, por este motivo, no âmbito de um projeto de investigação do Ministério Federal da Construção, e de uma proposta da Associação para a habitação e a Construção economicamente acessível, iniciou-se o trabalho do gestor do desenvolvimento no interior dos perímetros urbanos. Este gestor deverá apoiar as localidades no sentido de:

1. analisar os potenciais do desenvolvimento em áreas já urbanizadas,

2. dirigir-se aos proprietários e investidores, e

3. assim, procurar ativar de forma mais célere as reservas de terrenos de construção em situações variadas em termos dos direitos de construção, e

4. ser o nervo central da comunicação e negociação dos atores entre si, i.e., cidadãos, administração local, setor imobiliário, proprietários, arrendatários, etc. ${ }^{152}$

\section{Promover a descentralização e a qualidade de vida nas zonas rurais}

Distinta abordagem para uma política ativa, em detrimento de retrocessos promovidos por reformas legislativas, tem de ser a promoção equilibrada do território alemão, i.e., o apoio às zonas economicamente menos dinâmicas. A nova legislação é compreendida como necessária apenas nas zonas mais densamente habitadas e economicamente mais dinâmicas.

Recordamos que, na última década, migraram mais de 1,1 milhão de pessoas para as grandes cidades. Ao mesmo tempo, as zonas rurais perderam população. ${ }^{153} \mathrm{Em} 2015$, no Estado Federado de Sachsen-Anhalt, encontravam-se vagas $11,3 \%$ das habitações. ${ }^{154}$ Nas grandes

152 OEBBEKE, Alfons, Baulinks - unabhängiges Baufachmagazin, Links referentes a Construção - Revista Técnica da Construção, Bundesbauministerium und BBSR fördern "Innenentwicklungsmanager für den Wohnungsbau, Ministério Federal da Construção e o Instituto Federal para a investigação sobra a construção, a cidade e o espaço apoiam "Gestor para o desenvolvimento de áreas já urbanizadas para a construção de habitações, 19 de fevereiro de 2017, https://www.baulinks.de/webplugin/2017/0285.php4 153 OEBBEKE, Alfons, Baulinks - unabhängiges Baufachmagazin, Links referentes a Construção - Revista Técnica da Construção, Stadtentwicklungsbericht 2016 verabschiedet, Deliberação sobre o Relatório sobre 0 desenvolvimento das cidades, 17 de abril de 2017, https://www.baulinks.de/webplugin/2017/0611.php4

154 OEBBEKE, Alfons, Baulinks - unabhängiges Baufachmagazin, Links referentes a Construção - Revista Técnica da Construção, Kaum Wohnungsleerstand in Grossstädten, Nas cidades grandes quase não há habitações vagas, 6 de dezembro de 2016, https://www.baulinks.de/webplugin/2016/1775.php4 
cidades faltam, no entanto, habitações e o legislador reage abrindo mão dos solos naturais para construir habitações.

A coesão territorial é parte de um estado social e ecológico. Comparativamente à maior parte dos países industrializados, a Alemanha desenvolveu uma política de descentralização com muito bons resultados. Com políticas ativas de apoio às zonas menos privilegiadas, investiu-se na qualidade de vida, que, agora, ainda que com boas intenções, se resolve perturbar com soluções legislativas de curto prazo, de vistas curtas e contraproducentes, como se vai revelando a última reforma do Código Federal do Urbanismo.

\section{REFERÊNCIAS BIBLIOGRÁFICAS}

BATTIS, Ulrich/ MITSCHANG, Stephan/ REIDT, Olaf, Das Gesetz zur Umsetzung der Richtlinie 2014/52/EU im Städtebaurecht und zur Stärkung des neuen Zusammenlebens in der Stadt (BauGB-Novelle 2017), A lei da transposição da Diretiva 2014/52/UE no Direito do Urbanismo e para o reforço do novo tipo de convívio na cidade (Reforma do Código Federal do Urbanismo 2017), NVwZ Revista Nova da Administração, 2017, p. 817 - 836.

BOTHE, Anja, Vergleich des portugiesischen und deutschen Bauplanungs- und Sanierungsrechts im Hinblick auf die Zielsetzung einer sozial ausgeglichenen Wohnraumversorgung - Erfahrungen in den Metropolen Lissabon und Berlin, Instrumentos jurídicos de implementação do direito à habitação no direito do urbanismo alemão e português - experiências nas metrópoles Lisboa e Berlim, monografia, 323 p., Editora Lit, Münster, 2004.

BOTHE, Anja / JORGE, Maria do Rosário, Instrumentos novos para responder a desafios antigos de articulação no ordenamento do território - estudo das recentes reformas na legislação para o desenvolvimento espacial na Alemanha", in Revista do CEDOUA, n.o 35, 2015, ano XVIII_1.15, 1/22, p. 9, 27.

BOTHE, Anja, A classificação e a qualificação do solo no direito do urbanismo alemão, JURISMAT, Portimão, n.o 5, 2014, p. 271-285.

BOTHE, Anja, Direito do Urbanismo, do Ordenamento do Território e dos Solos em Portugal e na Alemanha, JURISMAT, Portimão, n.o 4, 2014, p. 289 - 319.

BOTHE, Anja, German law covering the public participation in planning and building infrastructure projects, in Albertina Dias, Bror Salmelin, David Pereira, Miguel Sales Dias, Modelling Innovation Sustainability and Technologies, Editora Springer, 2016 - (capítulo em livro sobre conferência em Oeiras, 22, 23 de Outubro de 2015), 16 p.

BUNDESRAT, Conselho Federal, Referência 806/16 (Beschluss) Decisão, 10 de fevereiro de 2017 Stellungnahme des Bundesrates, Posicionamento do Conselho Federal, Entwurf eines Gesetzes zur Umsetzung der Richtlinie 2014/52/EU im Städtebaurecht und zur Stärkung des neuen Zusammenlebens in der Stadt, Posta de Lei para a transposição da Diretiva 2014/52/UE no Direito do Urbanismo e para reforçar o novo tipo de convívio na cidade, https://www.umweltonline.de/PDFBR/2016/0806_2D16B.pdf. 
BUNDESVERBAND FREIER IMMOBILIEN- UND WOHNUNGSUNTERNEHMEN, União Federal de empresas independentes do setor imobiliário e da habitação, Mitglieder-Information, Informação para os membros, Bauplanungsrechtsnovelle aktuell, Atual: a reforma do Direito do Urbanismo, 4 de abril de 2017, https://www.bfw-bund.de/api/downloads/view/18781

BUNDESVERWALTUNGSGERICHT, Tribunal Federal Administrativo, BVerwG 4 CN 9.14, de 4 de novembro de 2015 , http://www.bverwg.de/entscheidungen/entscheidung.php?ent=041115U4CN9.14.0.

DEUTSCHER BUNDESTAG, Parlamento Federal Alemão, Gesetz über Massnahmen im Bauplanungsrecht zur Erleichterung der Unterbringung von Flüchtlingen, Lei de Medidas no Direito do Urbanismo para facilitar o alojamento de refugiados, de 20 de novembro de 2014, BGBI. I, Boletim Federal l, p. 1748, https://www.bgbl.de/xaver/bgbl/start.xav?start=\%2F\%2F*\%5B\%40attr_id\%3D\%27bgbl114s174 8.pdf\%27\%5D\#_bgbl_\%2F\%2F*\%5B\%40attr_id\%3D\%27bgbl114s1748.pdf\%27\%5D_150607 9123836.

DEUTSCHER BUNDESTAG, Parlamento Federal Alemão, Referência 18/10942, Gesetzentwurf der Bundesregierung, Proposta de lei do Governo Federal, Entwurf eines Gesetzes zur Umsetzung der Richtlinie 2014/52/EU im Städtebaurecht und zur Stärkung des neuen Zusammenlebens in der Stadt, Proposta da lei para a transposição da Diretiva 2014/52/EU no Direito Federal do Urbanismo e para o reforço do novo tipo de convívio na cidade, 23 de janeiro de 2017, p. 29, http://dip21.bundestag.de/dip21/btd/18/109/1810942.pdf

DEUTSCHER BUNDESTAG, Parlamento Federal Alemão, Gesetz zur Erleichterung von Planungsvorhaben für die Innenentwicklung der Städte, Lei para facilitar projetos de planeamento para o desenvolvimento de zonas já urbanizadas das cidades, de 21 de dezembro de 2006, BGBI. I S. 3316; http://www.krautzberger.info/assets/2012/03/BauGBNovelle_2007.pdf

DEUTSCHER BUNDESTAG, Gesetzentwurf der Bundesregierung - Entwurf eines Gesetzes zur Erleichterung von Planungsvorhaben für die Innenentwicklung der Städte, Proposta de lei do Governo Federal - Proposta de lei para facilitar empreendimentos de planeamento para 0 desenvolvimento do interior do perímetro urbano, de 4 de setembro de 2006, Referência 16/2496, p. 15, http://dip21.bundestag.de/dip21/btd/16/024/1602496.pdf.

DEUTSCHER BUNDESTAG, Parlamento Federal Alemão, Gesetz zur Stärkung der Innenentwicklung in den Städten und Gemeinden und weiteren Fortentwicklung des Städtebaurechts, Reforma para o desenvolvimento das áreas interiores ao perímetro urbano e do demais desenvolvimento do Direito do Urbanismo, de 11 de junho de 2013 Innenenwicklungsnovelle, Boletim Oficial Federal, BGBI. 2013 I, N. 29, p. 1548 - 1552, https://www.bgbl.de/xaver/bgbl/start.xav\#_bgbl_\%2F\%2F*\%5B\%40attr_id\%3D\%27bgbl113s 1548.pdf\%27\%5D_1506089434163.

DEUTSCHER BUNDESTAG Referência 17/11468, de 14 de novembro de 2012, Gesetzentwurf der Bundesregierung, Entwurf eines Gesetzes zur Stärkung der Innenentwicklung in den Städten und Gemeinden und weiteren Fortentwicklung des Städtebaurechts, Proposta de Lei do Governo Federal Alemão, na parte da fundamentação da nova lei: p. 9 
http://dipbt.bundestag.de/doc/btd/17/114/1711468.pdf.

DEUTSCHER BUNDESTAG, Parlamento Federal Alemão, Einbeziehung von Aussenbereichsflächen in das beschleunigte Verfahren, Inclusão de áreas exteriores ao perímetro urbano no procedimento acelerado, Referência WD $7-3000-001 / 17$, de 17 de janeiro de 2017, p. https://www.bundestag.de/blob/496940/fd90db88ec19bee622321eaa69dd5c9f/wd-7-001-17pdf-data.pdf.

DEUTSCHER BUNDESTAG, Parlamento Federal Alemão, Referência 16/3308, de 8 de novembro de 2006, Beschlussempfehlung und Bericht des Ausschusses für Verkehr, Bau und Stadtentwicklung zu dem Gesetz der Bundesregierung - Drucksachen 16/2496, 16/2932 -, Aconselhamento em relação a deliberação e relatório da comissão para o trânsito, e o desenvolvimento da construção e da cidade em relação a Lei do Governo Federal - Referências 16/2496, 16/2932 -, http://dipbt.bundestag.de/dip21/btd/16/033/1603308.pdf.

DEUTSCHES INSTITUT FÜR URBANISTIK, Instituto Alemão para Urbanística, cliente da elaboração do estudo: Bundesinstitut für Bau-, Stadt- und Raumforschung, Instituto Federal para a investigação referente a construção, a cidade e aos espaço: Planspiel zur Städtebaurechtsnovelle 2016/2017, Teste prático da aplicação do projeto de lei a casos concretos através da administração e outros participantes envolvidos, no total observaram representantes de seis municípios 30 exemplos, 31.1.2017, $117 \mathrm{p}$. https://difu.de/publikationen/2017/planspiel-zur-staedtebaurechtsnovelle-2016-2017.html.

EPINEY, Astrid, Umweltrecht der Europäischen Union, Nomos, 3ạ Ed., 2013, Baden-Baden, monografia, $616 \mathrm{p}$.

ERNST, Werner/ ZINKAHN, Willy/ BIELENBERG, Walter/ KRAUTZBERGER, Michael, Baugesetzbuch - Código Federal do Urbanismo anotado, Beck, 126 suplemento, 2017.

KRAUTZBERGER, Michael/ STÜER, Bernhard, Entwurf der Städtebaurechtsnovelle Projeto de reforma do Código Federal do Urbanismo, 2017, http://www.stueer.business.tonline.de/aufsatzc/baur0417.pdf.

KRAUTZBERGER, Michael/ STÜER, Bernhard, BauGB-Novelle 2014 II: Erleichterte Unterbringung von Flüchtlingen, Reforma II do Código Federal do Urbanismo: Alojamento facilitado de refugiados, in DVBI. Revista da Administração Alemã, 2, 2015, p. 73 - 79, http://www.stueer.business.t-online.de/aufsatzc/dvbl0215.pdf).

MESSERSCHMIDT, Klaus, Europäisches Umweltrecht, Beck, Munique, monografia, 1006 p.

MINISTROS DA UNIÃO EUROPEIA responsáveis pela Política de Coesão, pela Coesão Territorial e Assuntos Urbanos, Carta sobre Cidades Europeias Sustentáveis, adotada na reunião informal dos ministros responsáveis pelo desenvolvimento urbano e coesão territorial da União Europeia em 2007, http://www.forumdascidades.pt/?q=content/carta-de-leipzig-2007.

NATURSCHUTZBUND DEUTSCHLAND (NABU), Federação para a Proteção da Natureza, NABUStellungnahme zur Novellierung des BauGB, Gesetzentwurf der Bundesregierung vom 23. Januar 2017 (Drucksache 18/10942), Posicionamento da NABU referente a Reforma do Código 
Federal do Urbanismo, Proposta de lei do Governo Federal Alemão, de 23 de janeiro de 2017 https://www.nabu.de/imperia/md/content/nabude/nachbarnatur/170206_nabu-baugbnovelle_stellungnahme-.pdf.

OEBBEKE, Alfons, Baulinks - unabhängiges Baufachmagazin, Links referentes a Construção Revista Técnica da Construção, Kaum Wohnungsleerstand in Grossstädten, Nas cidades grandes quase não há habitações vagas, 6.12.2016, https://www.baulinks.de/webplugin/2016/1775.php4.

OEBBEKE, Alfons, Baulinks - unabhängiges Baufachmagazin, Links referentes a Construção Revista Técnica da Construção, Bundesbauministerium und BBSR fördern "Innenentwicklungsmanager für den Wohnungsbau, Ministério Federal da Construção e o Instituto Federal para a investigação sobra a construção, a cidade e o espaço apoiam "Gestor para o desenvolvimento de áreas já urbanizadas para a construção de habitações, 19 de fevereiro de 2017, https://www.baulinks.de/webplugin/2017/0285.php4.

OEBBEKE, Alfons, Baulinks - unabhängiges Baufachmagazin, Links referentes a Construção Revista Técnica da Construção, Stadtentwicklungsbericht 2016 verabschiedet, Deliberação sobre - Relatório sobre o desenvolvimento das cidades, 17 de abril de 2017, https://www.baulinks.de/webplugin/2017/0611.php4.

OLIVEIRA, Fernanda Paula: Direção Geral do Ordenamento do Território e do Desenvolvimento Urbano, Documento Técnico 8/2011.

OLIVEIRA, Fernanda Paula. Análise comparativa das Leis de Solo de Países Europeus, DireçãoGeral do Ordenamento do Território e do Desenvolvimento Urbano, Lisboa, 2004.

Urbanismo Comparado: o Paradigma do Modelo Alemão, in Conferência "Ordenamento do Território e Revisão dos Planos Diretores Municipais", Figueira da Foz, 8 e 9 de julho de 2003, p. 5.

PARLAMENTO EUROPEU E CONSELHO, Diretiva 85/337/CEE, de 27 de junho de 1985 alterada pela Diretiva 97/11/CE, pela Diretiva 2009/31/CE, e pela Diretiva 2011/92/UE, de 13 de dezembro de 2011, relativa à avaliação dos efeitos de determinados projetos públicos e privados no ambiente (codificação), http://eur-lex.europa.eu/legalcontent/PT/TXT/HTML/?uri=LEGISSUM:ev0032\&from=PT.

PARLAMENTO EUROPEU E CONSELHO, Diretiva 2001/42/CE, de 27 de junho de 2001, relativa à avaliação dos efeitos de determinados planos e programas no ambiente, Jornal Oficial no L 197 de 21/07/2001 p. 0030 - 0037, http://eur-lex.europa.eu/legalcontent/PT/TXT/HTML/?uri=CELEX:32001L0042\&from=PT.

STEINKE, Michael/ ZEMKE, Reinhold, Stadt/Ökonomie/Recht, Cidade/ Economia/Direito, Kommentar zur Städtebaurechtsnovelle 2017, Anotações a Reforma do Direito do Urbanismo 2017, Zu den Änderungen des BauGB und der BauNVO, Acerca das alterações do CFU e do RUGC, 16 de maio de 2017, http://stadt-oekonomie-recht.de/\%c2\%a7-kommentar/kommentarzur-staedtebaurechtsnovelle-2017/.

UVP-GESELLSCHAFT, Associação para a avaliação ambiental, Paukenschlag durch überarbeiteten Entwurf der BauGB-Novelle - Stellungnahme der UVP-Gesellschaft, Timpani através da proposta 
revista da reforma do Código Federal do Urbanismo - Posicionamento da Associação para a avaliação ambiental, 2017, http://www.uvp.de/de/uvp-recht/77-rechtsprechnung/887stellungnahme-der-uvp-gesellschaft.

VEREINIGUNG FÜR STADT-, REGIONAL- UND LANDESPLANUNG (SRL); BUND DEUTSCHER LANDSCHAFTSARCHITEKTEN, (bdl), União para o Planeamento da Cidade, da Região e do Estado Federado, Federação dos Arquitetos Paisagistas, Stellungnahme der SRL und des bdla zur Einführung des $\S 13 b$ BauGB, Posicionamento da SRL e da bdla acerca da introdução do $\S 13$, al. b, do CFU, motivo 11, 25 de janeiro 2017, http://www.srl.de/dateien/dokumente/de/Stellungnahme_BauGB2017_SRL_bdla.pdf.

Trabalho enviado em 10 de janeiro de 2018.

Aceito em 15 de fevereiro de 2018. 